\title{
1 A Rice Dual-localized Pentatricopeptide Repeat Protein is involved in Organellar 2 RNA Editing with MORFs
}

3

4 Running Title : A dual-localization PPR functions on RNA editing with MORFs

6 Haijun Xiao, Yanghong Xu, Chenzi Ni, Qiannan Zhang, Feiya Zhong, Jishuai Huang, Yingguo

7 Zhu, and Jun $\mathrm{Hu}^{*}$

$9 \quad{ }^{*}$ Corresponding author: junhu@ whu.edu.cn

11 State Key Laboratory of Hybrid Rice; Engineering Research Center for Plant Biotechnology and

12 Germplasm Utilization of Ministry of Education; College of Life Sciences, Wuhan University,

13 Wuhan 430072, China.

14

\section{Highlight}

16 We firstly characterized a dual-localized PPR protein which is required for RNA

17 editing in mitochondrion and chloroplast simultaneously. OsPGL1 binds to two 18 distinguish target transcripts directly and cooperated with MORFs.

\section{Abstract}

21 Flowering plants engage in diverse RNA editing events in mitochondrion and 22 chloroplast on post-transcriptional process. Although several PPRs and MORFs were 
23 identified as RNA editing factors, the underlying mechanism of PPRs and the

24 cooperation among them are still obscure. Here, we identified a rice dual-localized

25 PPR mutant Ospgl1. Loss-of-function of OsPGL1 resulted in defect of chloroplast

26 RNA editing at $n d h D-878$ and mitochondrial RNA editing at $c c m F c-543$, which can

27 be restored via complementary validation. Despite the synonymous editing on

$28 c c m F c-543$, loss of editing at $n d h D-878$ caused failure of conversion from serine to

29 leucine, leading to the dysfunction of chloroplast and defective in photosynthetic

30 complex, further studies demonstrated OsPGL1 directly bound to both two transcripts.

31 The interaction between three MORFs (MORF2/8/9) and OsPGL1 were confirmed in

32 vitro and in vivo, implied OsPGL1 functioned on RNA editing via an editosome. It

33 also suggested MORFs assisted and contributed to the flexible PPR-RNA recognition

34 model during RNA editing through the cooperation with PPRs. These results provide

35 new insight into the relationship between RNA editing and plant development on

36 chloroplast.

Key words: RNA editing, PPR, Chloroplast, Mitochondrial, MORF, Dual-localized

\section{Introduction}

RNA editing was broadly defined as a post-transcriptional process that changes the sequence of an RNA molecule from that of its DNA master (Covello and Gray, 1989).

43 RNA editing is widely spread in eukaryotic cell and highlighted in plant mitochondria 44 and chloroplasts. In animals, RNA editing was mediated by two mechanisms, one is 45 C-to-U editing by apolipoprotein B mRNA editing enzyme, catalytic (APOBEC) and 46 another is adenosine (A)-to-inosine (I) editing by adenosine deaminase acting on 47 RNA (ADAR) (Kim et al., 1994; Mehta and Driscoll, 2002; Melcher et al., 1996; 
Teng et al., 1993). In plants, RNA editing includes C-to-U, U-to-C and A-to-I conversion (Takenaka et al., 2013b). The majority of editing in plants occurs in mitochondrial and plastid transcripts, however, A-to-I editing also occurs in cytosolic tRNAs (Chateigner-Boutin and Small, 2010). RNA editing from C-to-U is the most frequent editing events in plants, in Arabidopsis and rice, 525 and $491 \mathrm{C}-$ to-U editing sites in mitochondria, 34 and $21 \mathrm{C}$-to-U editing sites in chloroplast has been identified in previous study (Chateigner-Boutin and Small, 2010). In human, the APOBEC3 proteins can deaminate cytidines to uridines in single-stranded DNA (ssDNA) (McDougall et al., 2011). Recently, the fusion of APOBEC3 with catalytically dead Cas9 (dCas9) or other Cas9 variants in CRISPR system accomplished the genomic editing of single bases in mammalian, yeasts and plants (Hess et al., 2016; Kim et al., 2017; Lu and Zhu, 2017; Ma et al., 2016; Zong et al., 2017). While in plants, the deaminase activity still need to be confirmed and elucidated. Researchers proposed RNA editing activity is governed by RNA-binding pentatricopeptide repeat (PPR) proteins, and DYW-subclass PPR proteins were considered as mainly RNA editing factors depend on its similarity with cytidine deaminases of the DYW motif (Salone et al., 2007)

\section{To date, several non-PPR editing factors, such as RNA editing factor interacting} proteins (RIPs)/multiple organellar RNA editing factors (MORFs), organelle RNA recognition motif (ORRM) proteins, organelle zinc-finger (OZ) proteins, and protoporphyrinogen oxidase 1 (PPO1) have been identified as components of the plant RNA apparatus (Sun et al., 2016). There were nine MORF proteins in Arabidopsis and five members in rice. MORF8/RIP1 was identified as an interacting factor of RARE1, a PPR protein required for RNA editing in Arabidopsis chloroplast (Bentolila et al., 2012). MORF2 and MORF9 were both targeted exclusively in plastids and can affect most of RNA editing sites in chloroplast in Arabidopsis (Takenaka et al., 2012). MORF2/8/9 can interact with ORRM6, which is involved in 
75 RNA editing of psbF-C77 and accD-C794 in Arabidopsis (Hackett et al., 2017).

76 Furthermore, MORFs also interact with each other and form a heterodimeric or 77 homodimeric complex, suggesting a more complicated regulation mechanism in 78 plants (Takenaka et al., 2012).

The PPR protein family was characterized by the degenerate motifs of 35 amino acids arranged as tandem repeats of 2-25 such elements, settled in a pair of antiparallel double alpha-helices, helices A and B (Small and Peeters, 2000; Yin et al., 2013). PPR proteins have been found to be in eukaryotic genomes and greatly expanded in the plants, study showed more than 400 members harbored into land plants (Cheng et al., 2016). PPR protein can be divided into two sub-families: P and PLS subfamilies, the $\mathrm{P}$ sub-families proteins contain tandem arrays of canonical 35-amino-acid (P) PPR repeats, whereas PLS sub-families characterized by triplets of P, L (i.e.35 to 36 amino acids in length), and S (i.e.31 amino acids) motifs (Lurin et al., 2004). Many post-transcriptional processes in these organelles were relevant to PPR proteins, including RNA editing, splicing, cleavage, RNA stability, and translation (Schmitz-Linneweber and Small, 2008). Most PPR proteins are targeted either mitochondria or chloroplasts, but few of them are dual-localization.

Here, we addressed a novel dual-localized PPR protein OsPGL1 in rice, which is required for RNA editing at two different cis elements. Loss of function of OsPGL1

94 caused a pale green leaves phenotype, resulting from defective photosynthetic complex in chloroplast development. Loss of editing at $n d h D-878$ caused failure of conversion from serine to leucine, which an extremely conserved amino acid in plants.

97 Further investigation showed OsPGL1 functions with MORF2/8/9 and directly binds 98 to $n d h D$ and $c c m F c$ via its 9 PPR motifs. These results confirmed PPR proteins and MORFs are required for RNA editing, and function together via a complex editosome. 


\section{Materials and Methods}

102

103 Plasmid construction and transformation

104 Two target sites at the $20 \mathrm{bp}$ upstream of protospacer-adjacent motif sequence (PAM)

105 according to the recognition principle of CRISPR/Cas9 were designed and analyzed

106 the specificity by CAS-OFFinder (http://www.rgenome.net/cas-offinder) (Table S1).

107 The target sequence joint was linked into gRNA-U3 and gRNA-U6 vector,

108 respectively followed by two rounds of nest-PCR. PCR products were subsequently

109 linked to CRISPR/Cas9 vector. The construction was identified through PCR and

110 sequencing. Calli derived from ZhongHua 11 (Oryza sativa. L. Japonica) were used

111 for Agrobacterium-mediated transformation. WT and CRISPR/Cas9 knockout lines

112 were grown in a paddy field and greenhouse in Wuhan, China under proper

113 management.

\section{Scanning electron microscopy and transmission electron microscopy assay}

116 For scanning electron microscopy assay, samples were prepared as described

117 previously (Zhou et al., 2011). Rice young leaves were cut into small section with a

118 razor and immediately placed in 70\% ethanol, 5\% acetic acid, and 4\% formaldehyde

119 for 18 h. Samples were critical point dried, sputter coated with gold in an E-100 ion

120 sputter, and observed with a scanning electron microscopy (Hitachi S-3000N, Japan).

121 For transmission electron microscopy, samples were fixed in $2.5 \%(\mathrm{w} / \mathrm{v})$

122 paraformaldehyde and $0.25 \%$ glutaraldehyde in $0.2 \mathrm{~N}$ sodium phosphate buffer for

$1232-4 \mathrm{~h}$ at $4{ }^{\circ} \mathrm{C}, \mathrm{pH} 7.0$, and were then post-fixed in $1 \% \mathrm{OsO}_{4}$ in $\mathrm{PBS}, \mathrm{pH}$ 7.4.

124 Following ethanol dehydration, samples were embedded in acrylic resin. Ultrathin 
125 sections (50 to $70 \mathrm{~nm})$ were double stained with $2 \%(\mathrm{w} / \mathrm{v})$ uranyl acetate and $2.6 \%$

$126(\mathrm{w} / \mathrm{v})$ lead citrate aqueous solution and examined with a transmission electron

127 microscope at $200 \mathrm{kV}$ (Tecnai G2 20 Twin, FEI, Netherlands).

\section{RNA Extraction and qRT-PCR}

130 Total RNA was extracted with $1 \mathrm{~mL}$ Trizol reagent according to the manufacturer's

131 instructions (Invitrogen). After isopropanol precipitation, the RNA was resuspended

132 in $30 \mu \mathrm{l}$ RNase-free water and treated with RNase-free DNase I (New England

133 Biolabs). First-strand cDNA was reverse transcribed using random primers (Primers

134 were listed in Table S2). Ubiquitin was detected as control for gene expression.

\section{Analysis of RNA editing}

137 For RNA editing analysis in the wild type and the Ospgll, total RNAs were isolated

138 from the young leaves using the Trizol reagent as described before (Hu et al., 2012).

139 RNA was treated with RNase-free DNase I (New England Biolabs), and confirmed by

140 PCR. Then, the RNAs were reverse transcribed with random primers and the

141 high-fidelity reverse transcriptase SuperScript III (Invitrogen). Primers were designed

142 to cover all 491 mitochondrial editing sites and 21 chloroplast editing sites (Table S2).

143 The RT-PCR products were sequenced directly.

\section{Subcellular localization of OsPGL1}

146 For transient expression in rice protoplast, 188 amino acid of the OsPGL1 N-terminal

147 were cloned into HBT-sGFP driven by the cauliflower mosaic virus 35S promoter to

148 construct the $35 \mathrm{~S}$ :OsPGL1 ${ }^{\mathrm{N1} 1-188}$ :sGFP fusion protein. Protoplast preparation and 
149 transformation procedures were as previously described (Yu et al., 2014).

150 MitoTracker Red (Invitrogen) was used as a mitochondrial specific dye.

\section{RNA electrophoresis mobility shift assays (REMSA)}

153 The corresponding cDNA fragments of OSPGL1 was amplified with specific primers

154 (Table S2), and cloned into the pGEX-6p-1 vector to create the fusion protein

155 GST-OsPGL1. Two RNA probes (probe 1 and probe 2) and negative control probe

156 (probe C) containing the target editing site were synthesized and labeled with biotin at

157 the 3' end by GenScript (Nanjing, China). For REMSA, the recombinant protein was

158 incubated with RNA probe in a $20 \mu 1$ reaction mixture including $10 \mu 1$ of $2 \times$ binding

159 buffer (100 mM Na phosphate, pH 7.5, 10 units RNasin, $0.1 \mathrm{mg} / \mathrm{mL}$ BSA, $10 \mathrm{mM}$

160 DTT, $2.5 \mathrm{mg} / \mathrm{mL}$ heparin, and $300 \mathrm{mM} \mathrm{NaCl}$ ). The mixture was incubated at $25^{\circ} \mathrm{C}$

161 for $30 \mathrm{~min}$, followed with separation by $5 \%$ native PAGE in $0.5 \times \mathrm{TBE}$ buffer and

162 transferred onto the nylon membrane (Roche). For the competitive REMSA, the

163 gradually increased concentration of the unlabeled probe was added into the reaction

164 mixture followed the procedure described above.

165

166 Complementation of Ospgl1 mutants

167 For complementation of the Ospgll mutant, a full-length (1815bp) cDNA fragment

168 was constructed into pCAMBIA-2300 vector driven by CMV-35S promoter and

169 transformed into Ospgl1-1 mutant background by agrobacterium-mediated method.

170 Independent transgenic lines were obtained and planted in Wuhan, China. 
173 The full-length cDNA of OsPGL1 and MORFs were cloned into pGBKT7 and

174 pGADT7 vector. The constructs were co-transformed into yeast (AH109 strain) in

175 pairs according to previous study (Hu et al., 2012).

176

177 GST pull-down assays

178 The purified recombinant proteins (GST tag, Trx-His tag, GST-OsPGL1,

179 Trx-MORF2-His, Trx-MORF8-His and Trx-MORF9-His) were dialyzed against

180 phosphate-buffered saline (PBS; $137 \mathrm{mM} \mathrm{NaCl}, 2.7 \mathrm{mM} \mathrm{KCl}, 10 \mathrm{mM} \mathrm{Na} 2 \mathrm{HPO}_{4}, 2$

$181 \mathrm{mM} \mathrm{KH}_{2} \mathrm{PO}_{4}$ ) for $24 \mathrm{~h}$ and quantified using thebicinchoninic acid (BCA) method. The

182 recombinant protein GST-OsPGL1 was incubated with glutathione sepharose for $1 \mathrm{~h}$

183 on ice and washed with five volumes of PBS for five times. Trx-His, Trx-MORFs-His

184 proteins were subsequently added to detect the interaction. The binding proteins were

185 washed with five volumes of PBS for five times, eluted with glutathione reductase

186 and separated by $10 \%$ SDS-PAGE. Products were transferred onto a polyvinylidene

187 fluoride (PVDF) membrane (BioRad), and investigated with antibodies against GST

188 and His respectively.

189

190 BiFC assays

191 For bimolecular fluorescence complementation (BiFC) analysis, the full-length cDNA

192 of OsPGL1 without the stop codon was fused to the C-terminal fragment of yellow

193 fluorescent protein (YFP) in pUC-SPYCE (C-terminal), MORF2, MORF8 and

194 MORF9 were fused to the N-terminal fragment of YFP in pUC-SPYNE (N-terminal).

195 The two vectors were co-transformed into rice protoplasts in pairs and observed by

196 bright-field and fluorescent microscopy using a Leica DM4000B microscopy (Hu et

197 al., 2012). 
199 Co-immunoprecipitation analysis

200 Total proteins from transgenic plants fused with FLAG (UBI: OsPGL1-FLAG) and

201 GFP (35S: MORFs-GFP) were extracted with extraction buffer (100 mM Tris-HCl, 202 200mM NaCl, 5 mM EGTA, 5 mM EDTA, 10 mM DTT, 0.6\% TritonX-100, $1 \mathrm{mM}$

203 PMSF, pH 8.0) and incubated with $2 \mu \mathrm{g}$ anti-GFP antibody overnight at $4^{\circ} \mathrm{C}, 100 \mu \mathrm{l}$ of 204 protein A-Sepharose beads was added and incubated for a further 3 to $4 \mathrm{~h}$. 205 Immunoprecipitates were washed for five times with co-immunoprecipitation buffer, 206 (150mM NaCl, 20mM Tris-HCl, 1mM EDTA, 0.2\% NP-40, 1 mM PMSF, pH 7.4) 207 and loaded in $6 \times \operatorname{SDS}$ loading buffer by denaturing for $10 \mathrm{~min}$. The proteins were 208 separated on a 10\% SD-SPAGE gel and detected by immunoblotting with anti-FLAG 209 and anti-GFP antibodies.

\section{Immunoblot analysis}

212 Total proteins were extracted from young leaves and quantified with the BCA protein 213 assay kit (Thermo scientific). $10 \mu \mathrm{g}$ total proteins were separated by SDS-PAGE, 214 transferred onto a polyvinylidene difluoride (PVDF) membrane (Bio-rad) and 215 incubated with various primary antibodies against NdhD (Beijing Protein Innovation, 216 China), PsaA, PsbA, PetA, AtpA, Lhca2 and Lhcb2 (Agrisera). Actin was used as a 217 reference antibody. Detection was carried out by the ECL western blotting detection 218 reagents (Bio-rad).

\section{Blue-native PAGE}

221 The equivalent of $500 \mu \mathrm{g}$ of total mitochondrial proteins from WT and Ospgll-1 
222 mutant were treated and loaded on BN-PAGE according to the previous protocol (Liu

223 et al., 2012). The gel was firstly stained with coomassie brilliant blue. For

224 immunoblotting, the gel was transferred to the PVDF membranes, antibodies against

225 Cytc1 were used to detect the accumulation of complex III.

\section{Accession numbers}

228 Sequence for rice OsPGL1, chloroplast NdhD, and mitochondrial gene CcmFc can be

229 found in the GenBank database under accession numbers XP_015618645.1 (OsPGL1),

230 NP_039444 (NdhD), YP_002000589 (CcmFc), respectively.

Results

\section{Phenotypic characterization of the Ospgl1 mutant}

235 We used Clustered Regularly Interspaced Short Palindromic Repeat (CRISPR) system

236 to generate several PPRs mutant under the background of the ZhongHua 11 (ZH11,

237 Oryza satia. L. Japonica) and obtained two independent transgenic knocked-out lines

238 of LOC_Os12g06650. Further genome DNA sequencing revealed a 41 bp deletion

239 from 288 to 328 and a 1 bp deletion at 530 in this PPR gene (Fig. 1A-C). Both two

240 lines exhibited pale green leaves at all vegetative stages (Fig. 1D-F), thus we named

241 this gene as pale green leaves 1 (Ospgl1) in this study. And we defined these two lines

242 as Ospgll-1 and Ospgl1-2, respectively. The content of chlorophyll was drastically

243 reduced than those in WT plants (Fig. 1G). This phenotype performed more

244 pronounced in paddy fields (Fig. S1A). Despite of the distinct development on

245 vegetative stage, the plant height, tiller number and seed setting were rarely impaired 
246 (Fig. 1H-J). To confirm the phenotype of Ospgll knockout mutants, we also generated

247 the transgenic RNAi lines. Results showed that suppression of OsPGL1 expression

248 recapitulated the knockout mutants phenotype (Fig. S2).

249 To dissect the morphologic details of the leaf, we performed scanning electron 250 microscopy (SEM) and transmission electron microscopy (TEM) examinations. SEM 251 results showed the leaf is complete and intact in WT (Fig. 2A), while some cracked 252 holes were distributed in the leaf of Ospgll-1 (Fig. 2F). Furthermore, TEM assays 253 showed the starch granular stacks in WT plant were well-balanced (Fig. 2B), while 254 the starch granular stacks in Ospgll-1 were reduced and incompact (Fig. 2G). When 255 we looked insight into the structure of thylakoid, results showed the density of 256 well-organized thylakoid were not observed in Ospgll-1, which exhibited more 257 hollow structures (Fig. 2C, 2H). In spite of the fact that chloroplasts were impaired, 258 the ultrastructure of the mitochondria was undistinguishable between WT and 259 Ospgll-1 (Fig. 2D, 2E and 2I, 2J). These observations revealed that the Ospgll 260 mutation primarily affects the development and morphology of chloroplasts rather 261 than mitochondria.

\section{OsPGLI encodes a DYW-motif containing protein}

264 OsPGL1 encodes a putative PPR protein consisting of 605 amino acids without intron.

265 Motif prediction analysis by Pfam (http://pfam.xfam.org/) revealed that OsPGL1 266 consists of 9 PPR motifs. $3 \mathrm{~S}$ motifs, 3 P motifs and $3 \mathrm{~L}$ motifs present staggered 267 arrangement ( Fig. S3A, 3B). The C-terminal region from residues 392 to 605 shows 268 the consensus sequences of the extension domains (E, E+, and DYW domains) (Fig. 269 S4). This data indicated that OsPGL1 belongs to the typical DYW type of PLS 270 subfamily. Alignment of OsPGL1 with its orthologs in various plants showed $75 \%$ 、 
$27175 \%, 46 \%, 51 \%, 51 \%, 47 \%$ similarity with Zea mays (GRMZM2G001466), Sorghum

272 bicolor (Sb08g003980), Arabidopsis thaliana (AT4G15720,REME2), Theobroma 273 cacao (XP_017974392), Glycine max (XP_003529581), and Brassica napus 274 (BnaC07g33170D) Fig. S4). Previous study reported that REME2 is involved in 275 RNA editing of rps3-1534 and rps4-175 in mitochondria (Bentolila et al., 2014). The 276 high similarity among OsPGL1, GRMZM2G001466 and Sb08g003980 implied the 277 function of this PPR gene might be conserved in monocots. Based on the PPR-RNA 278 recognition mode, we analyzed the conservation of the 1' and 6 amino acid of each 279 motif, which is essential for RNA recognition. Results showed these candidate 280 orthologs could be divided into two subgroup, monocots and dicots, which suggested 281 the functional conservation respectively (Fig. S5). It also implied the distinct function 282 between OsPGL1 and AtREME2.

\section{Expression pattern of $\boldsymbol{O S P G L 1}$}

285 To get insight into the expression pattern of $O s P G L 1$ in WT, RT-PCR and quantitative 286 RT-PCR (qRT-PCR) were employed to detect various tissues. RT-PCR Results 287 showed that OSPGL1 was constitutively expressed in both vegetative and 288 reproductive tissues, including root, stem, leaf, and panicle (Fig. 3A). Moreover, 289 qRT-PCR data showed the expression level in root, stem and panicle, but 290 preferentially accumulated in fresh leaf (Fig. 3B). These data are consistent with the 291 results of the leaf phenotype, and slightly effects on plant height and seed setting.

\section{OsPGL1 is a novel dual-localized PPR protein}

294 Plenty of reports confirmed that most PPR proteins are targeted to plastids, 295 chloroplast or mitochondrion. With bioinformatic analysis of TargetP 
296 (http://www.cbs.dtu.dk/services/TargetP/), OsPGL1 was predicted to localize into

297 chloroplast, and also into mitochondrion with a low degree of confidence. To make

298 sure of the subcellular localization of OsPGL1, the N-terminal region (amino acids

299 from 1 to 188) were fused with green flourecent protein (sGFP), driven by CaMV35S

300 promoter and transiently expressed in rice protoplast. Results showed the GFP signals

301 could overlap the red auto-fluorescent signals of chlorophyll (Fig. 3C). Interestingly,

302 there were still some spots could not overlap the signals from chloroplast, implied

303 OsPGL1 might target into mitochondria. Subsequently, mitotracker red were used to

304 indicate mitochondrion, which signals were also overlapped with the signals of

305 OsPGL1-GFP (Fig. 3D). Therefore, OsPGL1 is a novel dual-localized PPR protein in

306 rice, both targets into mitochondria and chloroplasts.

308 OsPGL1 is involved in C-to-U RNA editing of $\boldsymbol{n d h D}$ and $c c m F c$ transcripts

309 Studies showed PPR proteins were involved in the RNA editing of one or several

310 editing sites, especially in DYW subfamily (Sun et al., 2016). Consideration of the

311 dual-localization of OsPGL1, we checked all 491 editing sites in mitochondria and 21

312 editing sites in chloroplasts respectively by RT-PCR. Sequencing results revealed that

313 the C-to-U editing efficiency of $n d h D-878$ and $c c m F c-543$ dramatically decreased to

314 zero in both two mutants expect for $8 \%$ at $c c m F c-543$ in $O s p g l 1-2$, while $n d h D-878$

315 and $c c m F c-543$ were completed edited in WT (Fig. 4A). Consequently, abolishment

316 of editing in $n d h D-878$ recovered the codon from UUA to UCA, which resulted in the

317 amino acid substitution from leucine to serine. The loss of editing in another site

$318 c c m F c-543$, a mitochondrial RNA editing site converted the codon from GUU to

319 GUC, due to the degeneracy of codon, the change of the nucleotide at this position

320 does not cause any amino acid alteration, consistent with the results of no effects on

321 mitochondrion in Ospgll (Fig. 2I, 2J). 
322

323

324

325

326

327

328

329

330

331

332

333

334

335

336

337

338

339

340

341

342

343

344

345

346

347

To investigate the evolutionary conservation of the alteration from serine to leucine at the 293 position of $\mathrm{NdhD}$ protein sequence and valine at the 181 position of $\mathrm{CcmFc}$ protein sequence, the chloroplast $\mathrm{NdhD}$ orthologs and mitochondrial $\mathrm{CcmFc}$ orthologs from five representative species (Oryza sativa, zea mays, Arabidopsis thaliana, Nicotiana tabacum and Brassica napus) in plants were analyzed. Results showed these two residues are extremely conserved in the five tested species including monocots and dicots, implied that the leucine of $\mathrm{NdhD}$ and valine of $\mathrm{CcmFc}$ could important for plant development (Fig. 4B).

\section{OsPGL1 can bind to both $n d h D$ and $c c m F c$ transcripts}

To test the RNA binding activity of OsPGL1, we expressed recombinant OsPGL1 for further RNA electrophoresis mobility shift assays (REMSA). 9 PPR motifs from residues 46 to 605 was fused with a glutathione S-transferase (GST) tag for expression in Escherichia coli. The recombinant protein (GST-OsPGL1 ${ }^{46-605}$ ) was analyzed by western blot with anti-GST antibody to confirm the high purity (Fig. S7b). Subsequently, the recombinant protein was dialyzed to remove the contamination of RNase for REMSA and further quantified. The $n d h D$ and $c c m F c$ probes include 35 nucleotides surrounding the target editing sites were prepared and designated as probe 1 and probe 2. Probe C (nad3-155) was used as a negative control probe which has been reported as a specific target of another rice PPR protein (manuscript is preparing) (Fig. 5A). GST-OsPGL1 $1^{46-604}$ and GST tag were incubated with the biotin-labeled RNA probes, respectively. Both of the two protein-RNA complexes were detected as a shifted band that migrated more slowly than free RNA probe in the native gel, but no retarded band was observed when incubated with the GST (Fig. 5B, 5C). In addition, as negative control, no retarded band was observed when probe $\mathrm{C}$ was incubated with GST-OsPGL1 ${ }^{46-604}$. We next performed the competitor assay using 
348 non-labeled RNA probe with the same sequence, the binding intensity of the band

349 were decreased accompanied with the increased concentration of competitors (Fig. 5B,

350 5C). These data validated the OsPGL1 binds to both $n d h D$ and $c c m F c$ transcripts

351 directed via the PPR motifs. $n d h D$ and $c c m F c$ derived from chloroplast and

352 mitochondrion also confirmed the dual-localization of OsPGL1.

354 The transgenic complementation lines rescue the pale green phenotype

355 To verify whether the pale green phenotype resulted from the dysfunction of OsPGL1

356 in deed, we performed the transgenic complementation assay in mutant lines.

357 Full-length coding sequences of OsPGL1 was constructed into pCAMBIA-2300

358 vector driven by CaMV-35S promoter and transformed into Ospgl1-1 mutant by

359 Agrobacterium-mediated method. All 12 independent transgenic lines completely

360 rescued the mutant pale green leaves phenotype (Fig. 6A). Furthermore, we checked

361 the RNA editing efficiency of $n d h D-878$ and $c c m F c-543$ in all 12 independent

362 transgenic complementation lines, results showed 35S:OsPGL1 completely recovered

363 the RNA editing efficiency to $100 \%$ same as those in WT (Fig. 6B). Data indicates

364 that the pale green leaves phenotype was in deed caused by loss of RNA editing of

$365 n d h D-878$, which resulted from loss of function of OsPGL1.

367 OsPGL1 interacts with three MORF proteins in vitro and in vivo

368 In addition to PPR proteins, another group of RNA editing factors in plant organelle 369 was identified, the multiple organelle RNA editing factor (MORF) proteins, which has 370 also been termed RNA editing factor interacting protein (RIP) proteins. There were 371 five MORF proteins in rice, two of which were targeted exclusively in plastids, 372 MORF2 and MORF9. MORF8 was a dual-localized protein which targeted to 
373 mitochondria and plastids. The remaining two MORFs, MORF1 and MORF3 were

374 targeted to mitochondria. Because of the dual-localization of OsPGL1, we further

375 investigated the physical interactions between OsPGL1 and these MORF proteins in

376 pairs. Firstly, we performed yeast two-hybrid assay, data showed that OsPGL1 can

377 solid interact with three MORFs, MORF2, MORF8 and MORF9 in yeast. However,

378 no interaction was observed between OsPGL1 and other two MORFs as well as the

379 negative control (Fig. 7A). Interestingly, the interaction between OsPGL1 and

380 MORF9 was much more stronger than those of other MORFs. Moreover, the

381 interactions between OsPGL1 and MORF2/8/9 were also observed when we switched

382 the bait and prey in a yeast two-hybrid system (Fig. S6). Data displayed the stronger

383 interaction between OsPGL1 and MORF9, compared with others. Next, we performed

384 GST pull-down assays to validate the interactions in vitro, the three MORF proteins

385 were fused with His tag and OsPGL1 was fused with GST tag for expression (Fig.

386 S8A). Recombinant proteins were further verified by western blots (Fig. S8B) and

387 subjected for pull-down assay in pairs. Trx-MORF2-His, Trx-MORF8-His and

388 Trx-MORF9-His were all pulled down by GST-OsPGL1, respectively, which

389 demonstrated that OsPGL1 can interact with these three MORF proteins directly (Fig. 390 7B).

391 To test the interactions in vivo, we performed bimolecular fluorescence 392 complementation (BiFC) assays in rice protoplast. OsPGL1 and three MORFs were 393 fused to the C-terminal and N-terminal of yellow fluorescent protein (YFP), 394 respectively. Results showed that co-expression of OsPGL1-YFP and 395 MORF2-YFP ${ }^{\mathrm{N}} / \mathrm{MORF8}-\mathrm{YFP}^{\mathrm{N}} / \mathrm{MORF}-\mathrm{YFP}^{\mathrm{N}}$ exhibited strong signals overlapped 396 with chlorophyll, while the negative combination OsPGL1-YFP ${ }^{\mathrm{C}}$ and $\mathrm{YFP}^{\mathrm{N}} \mathrm{did}$ not 397 produce any detectable fluorescence signal (Fig. 7C). Interestingly, the signals from 398 OsPGL1-YFP $^{\mathrm{C}}$ and MORF8-YFP ${ }^{\mathrm{N}}$ were much more than chlorophyll, suggesting the 399 interaction in mitochondria, which consistent with the dual-localization of OsPGL1 
400

401

402

403

404

405

406

407

408

409

410

411

412

413

414

415

416

417

418

419

420

421

422

423

424

and MORF8.

Moreover, we generated the transgenic plants carrying UBI:OsPGL1-FLAG, 35S:MORF2-GFP, 35S:MORF8-GFP and 35S:MORF9-GFP, respectively. The protein crude extractions were incubated for co-immunoprecipitation assays with anti-GFP antibodies. Results confirmed the interactions between OsPGL1 and MORFs (Fig. 7D). Taken together, the results solidly demonstrated that OsPGL1 interacted with MORF2, MORF8 and MORF9 in vitro and in vivo.

\section{Ospgl1 exhibited defective in photosynthetic complex}

To make clear whether the photosynthetic and respiratory complex were impaired in Ospgll, we detected the proteins involved in photosynthesis and electronic transfer chains pathway. Firstly, we examined NdhD in WT, Ospgll mutants and the complementation line. Results showed greatly reduced accumulation of $\mathrm{NdhD}$, suggesting the loss of editing at $n d h D-878$ generated an unstable $\mathrm{NdhD}$ in chloroplast (Fig. 8A). Meanwhile, the accumulation of the photosystem I (PSI) subunits PsaA, PSII subunits PsbA, cytochrome b6f (PetA), chloroplast ATP synthase subunit AtpA, light harvesting complex of PSI (Lhca2) and light harvesting complex of PSII (Lhcb2) were also examined. All of these proteins were dramatically decreased in both two mutant lines (Fig. 8A). As expected, the levels of $\mathrm{NdhD}$ and other subunits in photosynthetic complex were recovered in the transgenic complementation line (Fig. 8A).

We next examined the proteins involved in mitochondrial electron transport chain pathway. Mitochondrial complexes isolated from calli of Ospgll-1 and WT were separated on blue-native gel. No obvious changes were observed in all of the complexes via coomassie blue staining, implying Ospgll did not compromise the 
425 function of mitochondria (Fig. 8B). Although the loss of RNA editing at $c c m F c-543$

426 did not change the amino acid, we detected mitochondrial complex III as well, since

$427 \mathrm{CcmFc}$ is a subunit of complex III. Protein immunoblotting with antibodies

428 anti-CytC1 showed no difference at the amount of complex III in Ospgll-1 compared

429 with that in WT (Fig. 8B), consistent with the undistinguishable morphological

430 structure of mitochondria between Ospgll and WT. Taken together, these results

431 indicated photosynthetic complex was impaired while the respiratory complex was

432 not affected in Ospgll mutants.

434 Altered expression of chloroplast development related genes in Ospgl1.

435 The development of chloroplast in plant is related to the coordinated expression of

436 both chloroplast and nuclear genes. Therefore, we first examined the transcript level

437 of the chloroplast-encoded genes at 5-leaf stage of Ospgll and WT plants, most of

438 which are mediated by two types of RNA polymerase: plastid-encoded polymerase

439 (PEP) and nuclear-encoded polymerase (NEP). Results showed that the expression

440 levels of PEP-dependent genes ( $r b c L$, psaA, psbA, and petB) were reduced in Ospgll,

441 which is consistent with results of the detection of protein level. Whereas, the

442 NEP-dependent genes: RNA polymerase ( $r p o A$ and rpoB) were activated in Ospgll

443 (Fig. 9A). Results implied that some retrograde signals from chloroplast might

444 activate NEP-dependent genes transcription for compensation in the development of 445 chloroplast.

446 Besides chloroplast-encoded genes, we also investigated the expression of some 447 nuclear-encoded genes related to chloroplast development and photosynthesis in 448 Ospgll and WT plants, including RNRS (encoding the large subunit of RNR), RpoTp 449 (encoding NEP core subunits), $C A B 1 R$ and $C A B 2 R$ (light-harvesting $\mathrm{Chl}$ a/b-binding 450 protein of PSII), HEMAl (encoding a glutamyl-tRNA reductase), $r b c S$ (encoding a 
451 Rubisco small subunit), YGL1 (encoding a chlorophyll synthetase) and CAO1

452 (encoding chlorophyll A oxygenase1). qRT-PCR analysis showed that the expression

453 level of these genes was reduced in the Ospgll mutant (Fig. 9B). Taken together,

454 these data indicated that OSPGL1 plays an important role in regulating the chloroplast

455 development and photosynthesis.

456

457 OsPGL1 recognizes the target RNA sequence

458 PPR protein binds target RNA via a modular recognition mechanism. To evaluate the

459 conservation of the P, L, S motifs of OsPGL1, the sequence of each motif were

460 analyzed. The alignments of these 9 motifs showed that residue Thr, Ala and Ser at

461 position 6, Asn and Asp at position 1' was conserved polar residues (Fig. 10A). More

462 interestingly, residue Gly is also highly conserved at position 16, especially

463 completely conserved at position 33 in P and L motifs (Fig. 10A). Data implied Gly

464 might be essential for the function of PPR motif. To evaluate the match degree of

465 OsPGL1 protein binding to its two target transcripts, we did a computational

466 prediction. Alignments of the target sites of OsPGL1 showed comparatively high

467 matches of PPR-RNA recognition basis with these two editing sites (Fig. 10B). The

468 alignments also suggested the combinations between PPR motifs and its targeted

469 nucleotides might be very flexible.

470

471

472

Discussion

473

474 OsPGL1 is a dual-localization PPR protein for RNA editing. 
475 PPR proteins were confirmed as a trans-acting factor for organelle RNA and acted as

476 site specific RNA binding proteins (Okuda et al., 2006). Most PPRs were involved in

477 organelle RNA editing either mitochondrion or chloroplasts specifically, few of them

478 are dual-localization. SOAR1 is a cytosol-nucleus dual-localized pentatricopeptide

479 repeat (PPR) protein, which acting downstream of CHLH/ABAR and upstream of a

480 nuclear ABA-responsive bZIP transcription factor ABI5 (Jiang et al., 2015). PNM1 is

481 dual localized to mitochondria and nuclei in Arabidopsis, which was only associated

482 with polysomes and played a role in translation in mitochondria, and interacted with

483 TCP8 in the nucleus (Hammani et al., 2011). Both PPR2263 and MEF29 dually

484 targeted to mitochondria and chloroplasts, and are required for RNA editing in maize

485 and Arabidopsis, respectively (Sosso et al., 2012). Here, we firstly reported a novel

486 dual-localization PPR protein to mitochondria and chloroplasts in rice. Our data

487 showed OsPGL1 is also required for RNA editing, and binds to target RNA directly.

488 Both $n d h D-878$ (chloroplast) and $c c m F c-543$ (mitochondrion) were completely edited

489 in WT, even though the editing of $c c m F c-543$ (mitochondrion) is synonymous. Loss

490 of function of OsPGL1 leads to the editing efficiency decrease to zero, and resulted in

491 the pale green leaf phenotype. The dual-localization of OsPGL1 suggested the signal

492 peptide sequence of OsPGL1 could be applied for trans-locating an artificial protein

493 for mitochondria and chloroplasts synchronously in future.

494

495 OsPGL1 recognizes target RNAs and functions with MORF proteins

496 The PPR motif consists of two anti-parallel $\alpha$-helixes, the binding specificity depend

497 on the first $\alpha$-helix (Barkan et al., 2012). Bioinformatic and structural analysis

498 indicated that three positions of amino acids distributed in two adiacent PPR repeats

499 were of great importance in recognizing its target RNA base (Takenaka et al., 2013a).

500 The alignment of OsPGL1 showed that high conservation of these positions in 
501 monocots (Fig. S5), implying the conserved function of those orthologs genes in RNA

502 editing of $n d h D$ and $c c m F c$ in monocots. OsPGL1 was a DYW subgroup PPR protein 503 with 3 P, 3 L and 3S motifs. More interesting finding is that the highly conservation of 504 Gly and Ala at position 16, and completely conservation of Gly at position 33 in P and 505 L motifs, which could be important for the function of PPR proteins. In this study, the 506 RNA recognition also follows the rules that the editing site is located at downstream 507 of binding sites, and the interval space is 4 nucleotides. In a word, such modular mode 508 can help us to deeply understand the RNA recognition of PPR proteins and its 509 application in future.

510 Non-PPR editing factors RIPs/MORFs, ORRM, OZ, and PPO1 have been 511 identified as components of the plant RNA editosome, which was required for RNA 512 editing (Sun et al., 2016). In Arabidopsis plastids, both of the two plastid-localized 513 members, MORF2 and MORF9 were required for RNA editing for mostly sites 514 (Takenaka et al., 2012). Recent study showed the RNA-binding activity of an 515 artificial (PLS) ${ }_{3}$ PPR could be sharply increased upon MORF9 binding, suggested the 516 interaction between PPR and MORF9 could be more vital than that of others (Yan et 517 al., 2017). In Arabidopsis, CLB19 interacted with MORF2, PDM2 interacted with 518 MORF2/9, all of PDM1/SEL1, PPO1 and ORRM6 interacted with MORF2/8/9 (Du et 519 al., 2017; Hackett et al., 2017; Ramos-Vega et al., 2015; Zhang et al., 2014; Zhang et 520 al., 2015). All these data indicated the editosome in plant is quite complicated. 521 Nevertheless, MORF proteins were rarely reported in rice. Recently, WSP1, a 522 sequence similarity with MORF protein was identified in rice, which was involved in 523 RNA editing and splicing of several plastid genes (Zhang et al., 2017). In our study, 524 we confirmed that OsPGL1 can also interact with MORF2, MORF8 and MORF9 in 525 vitro and in vivo. The interaction between OsPGL1 and MORF9 was significant 526 stronger than that of others, implying the RNA binding activities of OsPGL1 could be 527 enhanced by cooperation with MORF9. According to our data, we believe that 
528 OsPGL1 conducts the organelle RNA editing via an editosome coupled with MORF

529 proteins. Other factors or subunits of editosome will be further explored based on our

530 transgenic plants carrying UBI: OsPGL1-FLAG, 35S:MORF2-GFP,

531 35S:MORF8-GFP and 35S:MORF9-GFP.

532

533 OsPGL1 plays an important role in rice chloroplast development

534 Leaf is an important tissue for plant. In this study, we constructed CRISPR/Cas9

535 knockout mutants of PPR gene OsPGL1, Ospgll-1 and Ospgl1-2, both of which

536 exhibited pale green leaves during the whole vegetative stages. Further investigation

537 revealed the chloroplast development and photosynthesis were defective on RNA and

538 protein level in the mutant. NEP-dependent genes were activated in mutant implied

539 some unknown retrograde signals from chloroplast were involved in compensation

540 effects in the development of chloroplast. Complementation lines could rescue this

541 aberrant phenotype, suggested that the base deletion mutation in OsPGL1 gene was

542 responsible for the PGL phenotype. OsPGL1 regulated chloroplast development by

543 organelle RNA editing of $n d h D$. The highly conserved leucine at NdhD-293 is

544 important for the structure or function of NdhD. We proposed the loss of RNA editing

545 might lead to unstable $\mathrm{NdhD}$ in chloroplast, based on the results of protein

546 immunoblotting, which showed the amount of photosynthetic complex subunits were

547 dramatically decreased in mutants. Results suggested that PPR genes play a vital role

548 in regulating chloroplast development via RNA editing in plant.

\section{Acknowledgements}

551 We thank Yaoguang Liu laboratory for providing us with pYLCRISPR/Cas9 vectors.

552 No conflict of interest declared 


\section{Author contributions}

555 H.X., J.Hu. and Y.Z. designed the study. H.X. and Q.Z. contributed to constructed and 556 Ospgl1-1, Ospgll-2 mutants and RNAi lines. H.X. and Y.X. carried out most 557 experiments, H.X. and Q.Z. conducted SEM and TEM, F.Z. and C.N. performed 558 expression and purification of recombinant proteins, J.Huang. contributed to field 559 managements, H.X. and J.Hu. wrote the manuscript with feedback from all authors.

\section{$561 \quad$ Funding information}

562 This work is supported by funds from the National Key Research and Development 563 Program of China (2016YFD0100804), the National Natural Science Foundation of 564 China (31371698 and 31670310) and Suzhou Science and Technology Foundation 565 (SNG2017061).

\section{Supplemental data}

569 Figure S1. Phenotype of the Ospgll and WT in a paddy field.

570 Figure S2. Phenotype of WT and RNAi line.

571 Figure S3. Schematic structural sequence of OsPGL1.

572 Figure S4. Sequence alignment of $O S P G L 1$ with its orthologs in various plants.

573 Figure S5. Conservation of the amino acid at 6 and 1' position of each PPR motif.

574 Figure S6. Interaction of OsPGL1 with MORF2/MORF8/MORF9 by yeast 
575 two-hybrid assay.

576 Figure S7. Expression and purification of GST-OsPGL1 ${ }^{46-604}$.

577 Figure S8. Expression and purification of Trx-MORF2-His, Trx-MORF8-His and 578 Trx-MORF9-His.

579 Table S1. Design of target adaptor for CRISPR/Cas9 system.

580 Table S2. Primers used for qRT-PCR, vector construction and RNA editing.

\section{References}

587 Bentolila S, Babina AM, Germain A, Hanson MR. 2014. Quantitative trait locus 588 mapping identifies REME2, a PPR-DYW protein required for editing of specific C targets in Arabidopsis mitochondria. RNA Biol 10, 1520-1525.

590 Bentolila S, Heller WP, Sun T, Babina AM, Friso G, van Wijk KJ, Hanson MR.

591 2012. RIP1, a member of an Arabidopsis protein family, interacts with the protein 592 RARE1 and broadly affects RNA editing. Proc Natl Acad Sci U S A 109, E1453-1461.

593 Chateigner-Boutin AL, Small I. 2010. Plant RNA editing. RNA Biol 7, 213-219.

594 Cheng S, Gutmann B, Zhong X, Ye Y, Fisher MF, Bai F, Castleden I, Song Y, 595 Song B, Huang J, Liu X, Xu X, Lim BL, Bond CS, Yiu SM, Small I. 2016. 596 Redefining the structural motifs that determine RNA binding and RNA editing by 597 pentatricopeptide repeat proteins in land plants. Plant J 85, 532-547.

598 Covello PS, Gray MW. 1989. RNA editing in plant mitochondria. Nature 341, 599 662-666.

600 Du L, Zhang J, Qu S, Zhao Y, Su B, Lv X, Li R, Wan Y, Xiao J. 2017. The 
601 Pentratricopeptide Repeat Protein Pigment-Defective Mutant2 is Involved in the 602 Regulation of Chloroplast Development and Chloroplast Gene Expression in 603 Arabidopsis. Plant Cell Physiol 58, 747-759.

604 Hackett JB, Shi X, Kobylarz AT, Lucas MK, Wessendorf RL, Hines KM, 605 Bentolila S, Hanson MR, Lu Y. 2017. An Organelle RNA Recognition Motif Protein 606 Is Required for Photosystem II Subunit psbF Transcript Editing. Plant Physiol 173, $607 \quad 2278-2293$.

608 Hammani K, Gobert A, Hleibieh K, Choulier L, Small I, Giege P. 2011. An 609 Arabidopsis dual-localized pentatricopeptide repeat protein interacts with nuclear 610 proteins involved in gene expression regulation. Plant Cell 23, 730-740.

611 Hess GT, Fresard L, Han K, Lee CH, Li A, Cimprich KA, Montgomery SB, 612 Bassik MC. 2016. Directed evolution using dCas9-targeted somatic hypermutation in 613 mammalian cells. Nat Methods 13, 1036-1042.

614 Hu J, Wang K, Huang W, Liu G, Gao Y, Wang J, Huang Q, Ji Y, Qin X, Wan L, 615 Zhu R, Li S, Yang D, Zhu Y. 2012. The rice pentatricopeptide repeat protein RF5 616 restores fertility in Hong-Lian cytoplasmic male-sterile lines via a complex with the 617 glycine-rich protein GRP162. Plant Cell 24, 109-122.

618 Jiang SC, Mei C, Liang S, Yu YT, Lu K, Wu Z, Wang XF, Zhang DP. 2015. 619 Crucial roles of the pentatricopeptide repeat protein SOAR1 in Arabidopsis response 620 to drought, salt and cold stresses. Plant Mol Biol 88, 369-385.

621 Kim D, Lim K, Kim ST, Yoon SH, Kim K, Ryu SM, Kim JS. 2017. Genome-wide 622 target specificities of CRISPR RNA-guided programmable deaminases. Nat 623 Biotechnol 35, 475-480.

624 Kim U, Wang Y, Sanford T, Zeng Y, Nishikura K. 1994. Molecular cloning of 625 cDNA for double-stranded RNA adenosine deaminase, a candidate enzyme for 626 nuclear RNA editing. Proc Natl Acad Sci U S A 91, 11457-11461.

627 Liu G, Tian H, Huang YQ, Hu J, Ji YX, Li SQ, Feng YQ, Guo L, Zhu YG. 2012. 628 Alterations of mitochondrial protein assembly and jasmonic acid biosynthesis 629 pathway in Honglian (HL)-type cytoplasmic male sterility rice. J Biol Chem 287, $630 \quad 40051-40060$.

631 Lu Y, Zhu JK. 2017. Precise Editing of a Target Base in the Rice Genome Using a 
632 Modified CRISPR/Cas9 System. Mol Plant 10, 523-525.

633 Lurin C, Andres C, Aubourg S, Bellaoui M, Bitton F, Bruyere C, Caboche M, 634 Debast C, Gualberto J, Hoffmann B, Lecharny A, Le Ret M, Martin-Magniette 635 ML, Mireau H, Peeters N, Renou JP, Szurek B, Taconnat L, Small I. 2004. 636 Genome-wide analysis of Arabidopsis pentatricopeptide repeat proteins reveals their 637 essential role in organelle biogenesis. Plant Cell 16, 2089-2103.

638 Ma Y, Zhang J, Yin W, Zhang Z, Song Y, Chang X. 2016. Targeted AID-mediated 639 mutagenesis (TAM) enables efficient genomic diversification in mammalian cells. Nat 640 Methods 13, 1029-1035.

641 McDougall WM, Okany C, Smith HC. 2011. Deaminase activity on single-stranded 642 DNA (ssDNA) occurs in vitro when APOBEC3G cytidine deaminase forms 643 homotetramers and higher-order complexes. J Biol Chem 286, 30655-30661.

644 Mehta A, Driscoll DM. 2002. Identification of domains in apobec-1 645 complementation factor required for RNA binding and apolipoprotein-B mRNA 646 editing. RNA 8, 69-82.

647 Melcher T, Maas S, Herb A, Sprengel R, Seeburg PH, Higuchi M. 1996. A 648 mammalian RNA editing enzyme. Nature 379, 460-464.

649 Okuda K, Nakamura T, Sugita M, Shimizu T, Shikanai T. 2006. A 650 pentatricopeptide repeat protein is a site recognition factor in chloroplast RNA editing. 651 J Biol Chem 281, 37661-37667.

652 Ramos-Vega M, Guevara-Garcia A, Llamas E, Sanchez-Leon N, Olmedo-Monfil 653 V, Vielle-Calzada JP, Leon P. 2015. Functional analysis of the Arabidopsis thaliana 654 CHLOROPLAST BIOGENESIS 19 pentatricopeptide repeat editing protein. New 655 Phytol 208, 430-441.

656 Salone V, Rudinger M, Polsakiewicz M, Hoffmann B, Groth-Malonek M, Szurek 657 B, Small I, Knoop V, Lurin C. 2007. A hypothesis on the identification of the editing 658 enzyme in plant organelles. FEBS Lett 581, 4132-4138.

659 Schmitz-Linneweber C, Small I. 2008. Pentatricopeptide repeat proteins: a socket 660 set for organelle gene expression. Trends Plant Sci 13, 663-670.

661 Small ID, Peeters N. 2000. The PPR motif - a TPR-related motif prevalent in plant 
662 organellar proteins. Trends Biochem Sci 25, 46-47.

663 Sosso D, Mbelo S, Vernoud V, Gendrot G, Dedieu A, Chambrier P, Dauzat M,

664 Heurtevin L, Guyon V, Takenaka M, Rogowsky PM. 2012. PPR2263, a

665 DYW-Subgroup Pentatricopeptide repeat protein, is required for mitochondrial nad5

666 and cob transcript editing, mitochondrion biogenesis, and maize growth. Plant Cell 24,

667 676-691.

668 Sun T, Bentolila S, Hanson MR. 2016. The Unexpected Diversity of Plant Organelle

669 RNA Editosomes. Trends Plant Sci 21, 962-973.

670 Takenaka M, Zehrmann A, Brennicke A, Graichen K. 2013a. Improved

671 computational target site prediction for pentatricopeptide repeat RNA editing factors.

672 PLoS One 8, e65343.

673 Takenaka M, Zehrmann A, Verbitskiy D, Hartel B, Brennicke A. 2013b. RNA

674 editing in plants and its evolution. Annu Rev Genet 47, 335-352.

675 Takenaka M, Zehrmann A, Verbitskiy D, Kugelmann M, Hartel B, Brennicke A.

676 2012. Multiple organellar RNA editing factor (MORF) family proteins are required

677 for RNA editing in mitochondria and plastids of plants. Proc Natl Acad Sci U S A 109,

678 5104-5109.

679 Teng B, Burant CF, Davidson NO. 1993. Molecular cloning of an apolipoprotein B 680 messenger RNA editing protein. Science 260, 1816-1819.

681 Yin P, Li Q, Yan C, Liu Y, Liu J, Yu F, Wang Z, Long J, He J, Wang HW, Wang J, 682 Zhu JK, Shi Y, Yan N. 2013. Structural basis for the modular recognition of 683 single-stranded RNA by PPR proteins. Nature 504, 168-171.

684 Yu C, Wang L, Chen C, He C, Hu J, Zhu Y, Huang W. 2014. Protoplast: a more 685 efficient system to study nucleo-cytoplasmic interactions. Biochem Biophys Res 686 Commun 450, 1575-1580.

687 Zhang F, Tang W, Hedtke B, Zhong L, Liu L, Peng L, Lu C, Grimm B, Lin R. 688 2014. Tetrapyrrole biosynthetic enzyme protoporphyrinogen IX oxidase 1 is required 689 for plastid RNA editing. Proc Natl Acad Sci U S A 111, 2023-2028.

690 Zhang HD, Cui YL, Huang C, Yin QQ, Qin XM, Xu T, He XF, Zhang Y, Li ZR, 691 Yang ZN. 2015. PPR protein PDM1/SEL1 is involved in RNA editing and splicing of 
692 plastid genes in Arabidopsis thaliana. Photosynth Res 126, 311-321.

693 Zhang Z, Cui X, Wang Y, Wu J, Gu X, Lu T. 2017. The RNA Editing Factor WSP1

694 Is Essential for Chloroplast Development in Rice. Mol Plant 10, 86-98.

695 Zhou S, Wang Y, Li W, Zhao Z, Ren Y, Wang Y, Gu S, Lin Q, Wang D, Jiang L, 696 Su N, Zhang X, Liu L, Cheng Z, Lei C, Wang J, Guo X, Wu F, Ikehashi H, Wang

697 H, Wan J. 2011. Pollen semi-sterility1 encodes a kinesin-1-like protein important for 698 male meiosis, anther dehiscence, and fertility in rice. Plant Cell 23, 111-129.

699 Zong Y, Wang Y, Li C, Zhang R, Chen K, Ran Y, Qiu JL, Wang D, Gao C. 2017. 700 Precise base editing in rice, wheat and maize with a Cas9-cytidine deaminase fusion. $701 \quad$ Nat Biotechnol 35, 438-440.

702

703

$704 \quad$ Figure legends

705

706 Figure 1. Mutant and phenotypic characterization of Ospgl1

707 (A) Schematic drawing of the intronless gene OsPGLI attaching the position of 708 the deletion in Ospgll.

709 (B) Alignment of WT and mutant DNA sequences around the target sites highlighting 710 the deletion of $41 \mathrm{bp}$ in Ospgl1-1 and 1bp deletion in Ospgl1-2 marked with a pink 711 box.

712 (C) Sequencing results of Ospgll-1 and Ospgll-2 heterozygotes.

713 (D) Comparison of leaves from Ospgl1-1 and WT plant at the two-leaf stage, the red 714 box shows magnified view, bar $=2 \mathrm{~cm}$.

715 (E) Comparison of leaves from Ospgll-1 and WT plant at the three-leaf stage, the red 
716 box shows magnified view, bar $=2 \mathrm{~cm}$.

717 (F) Comparison of leaves from Ospgll-1 and WT plant at the tillering stage, the red

718 box shows magnified view, bar $=5 \mathrm{~cm}$.

719 (G)Comparison of the chlorophyll content in Ospgl1-1 and WT. Bars represent mean

$720 \pm$ SD from three independent biological replicates. Asterisks indicate statistically

721 significant differences compared with the WT (Student's t-test: *** $\mathrm{P}<0.001$ ).

722 (H)Comparison of the plant height of Ospgl1-1 and WT plant.

723 (I) Comparison of the tiller number of Ospgl1-1 and WT plant.

724 (J) Comparison of the seed setting of Ospgl1-1 and WT plant.

728 (A) Scanning electron microscopy image of WT leaf, bar $=20 \mu \mathrm{m}$

729 (B) Transmission electron microscopy image of WT chloroplasts, bar $=2 \mu \mathrm{m}$

730 (C) A higher magnification image of WT chloroplast from (B), bar $=0.3 \mu \mathrm{m}$

731 (D) Transmission electron microscopy image of WT mitochondria, bar $=0.5 \mu \mathrm{m}$

732 (E) A higher magnification image of WT mitochondrion from (D), bar $=0.15 \mu \mathrm{m}$

733 (F) Scanning electron microscopy image of mutant leaf, the image shows a defective

734 Leaf surface morphology with cracked, broken holes at the pale parts of Ospgll-1, bar $735=20 \mu \mathrm{m}$

736 (G) Transmission electron microscopy image of chloroplasts in pale parts of Ospgl1-1 737 mutant leaf, the image shows incompact granal stacks and lacked well-structured 
738 thylakoid, bar $=1 \mu \mathrm{m}$

739 (H) A higher magnification image of chloroplast in pale parts of Ospgl1-1 mutant leaf 740 from $(\mathbf{G})$, bar $=0.3 \mu \mathrm{m}$

741 (I) Transmission electron microscopy image of mitochondria in Ospgl1-1 leaf, bar = $7420.3 \mu \mathrm{m}$

743 (J) A higher magnification image of Ospgll-1 mitochondrion from (I), bar $=0.15 \mu \mathrm{m}$

Figure 3. Expression and subcellular localization analysis of $O S P G L 1$

746 (A) RT-PCR examination of $O s P G L 1$ in different tissues of WT. R, Root; S, Steam; 747 L3, three-leaf stage; L4, four-leaf stage; L5, three-leaf stage, five-leaf stage; P, $748 \quad$ panicle.

749 (B) Real time RT-PCR examination of OsPGL1 in different tissues of WT. Error bars $750 \quad$ represent the SD.

751 (C) Transient expression of 35S:sGFP (top) and 35S:OsPGL1 ${ }^{\mathrm{N} 1-188}{ }_{\text {-sGFP (bottom) in }}$ 752 rice protoplast. $\mathrm{Bar}=5 \mu \mathrm{m}$.

753 (D) Transient expression of 35S:sGFP (top) and 35S:OsPGL1 ${ }^{\text {N1-188 }}$-sGFP (bottom) in 754 rice protoplast. MitoTracker Red were used for mitochondria indicator. Bar = 5 $755 \mu \mathrm{m}$.

756

757 Figure 4. Organelle RNA editing analysis in different species

758 (A) RNA editing analysis of the $n d h D-878$ and $c c m F c-543$ sites from WT and 759 Ospgll-1 leaves. The black stars marks the editing site, the editing efficiency was 
$760 \quad$ presented under the target sites.

761 (B) Alignment of the orthologous $\mathrm{NdhD}$ and $\mathrm{CcmFc}$ amino acids sequences in five

762 different species around the corresponding affected residues. Numbers and the red 763 rectangular box indicate the converted amino acid.

764

\section{Figure 5. OsPGL1 possesses specific RNA binding activities}

766 (A) Schematic sequences of RNA probes. Edited sites were indicated and marked in 767 red letter. Probe $\mathrm{C}$ is a negative control in this study.

768 (B) RNA electrophoresis mobility shift assays (REMSA) of GST-OsPGL1 ${ }^{46-605}$ and 769 GST-tag with RNA probe 1. Unlabeled probe 1 was used as competitor at a range 770 of the concentrations for competitive REMSA. GST-tag and probe $\mathrm{C}$ were used as $771 \quad$ negative control.

772 (C) RNA electrophoresis mobility shift assays (REMSA) of GST-OsPGL1 ${ }^{46-605}$ and 773 GST-tag with RNA probe 2. Unlabeled probe 2 was used as competitor at a range 774 of the concentrations for competitive REMSA. GST-tag and probe $\mathrm{C}$ were used as 775 negative control.

776

\section{Figure 6. Complementation analysis of Ospgl1-1}

778 (A) The phenotypes of WT, Ospgll-1 and complemented $\mathrm{T}_{0}$ plant (com) at the 779 tillering stage. bars $=5 \mathrm{~cm}$.

780

(B) RNA editing efficiency of $n d h D-878$ and $c c m F c-543$ comparison among WT, 781 Ospgll-1 and complemented $\mathrm{T}_{0}$ plant (com), the stars show editing sites. 


\section{Figure 7. OsPGL1 directly interacts with MORF2/8/9 proteins}

784 (A) Yeast-two hybrid assay, pGAD, GAL4 activation domain, used as prey vector, 785 pGBK, GAL4 DNA binding domain, used as bait vector, SD/-TL and SD/-TLHA 786 indicate SD/-Trp-Leu and SD/-Trp-Leu-His-Ade dropout plates, respectively. 787 pGBK-53 and pGBK-lam was used as positive and negative control. Co-transcription of pGAD-T and pGBK-OsPGL1 used for self-activation

(B) GST Pull-down assay, the interaction between OsPGL1 and MORF2/8/9 proteins 791 with detected by GST Pull-down assay, respectively. GST and Trx-His tag protein was used as control. The eluates were immunoblotted with anti-GST and anti-His antibodies, respectively.

794

(C) Bimolecular fluorescence complementation assay showing that OsPGL1-YFP 795 interacts with MORF2- $\mathrm{YFP}^{\mathrm{N}}, \mathrm{MORF8}-\mathrm{YFP}^{\mathrm{N}}$ and MORF9- $\mathrm{YFP}^{\mathrm{N}}$ to produce YFP fluorescence in the chloroplasts. Bar $=5 \mu \mathrm{m}$.

(D) Co-immunoprecipitation assay detection with anti-FLAG and anti-GFP antibodies, respectively.

802 (A) Immunoblot analysis of the subunits of photosynthetic complex in WT, Ospgll 803 mutants, and complementation line at 4-leaf stage. Actin served as reference 804 antibody, CBB staining indicated the loading control. Lanes were loaded with a 805 series of dilutions as indicated.

806 (B) The level of major protein of mitochondrial respiratory complex III analysis by 
BN-PAGE (left) and immunoblot (right). Cytc1 was used as a representative

808 subunit of complex III.

809

810 Figure 9. Expression Analysis of chloroplast development related genes

811 (A) Real time RT-PCR examination of PEP-dependent genes ( $r b c L, p s a A, p s b A$, and

812 petB) and NEP-dependent genes $(r p o A$ and rpoB) in WT and Ospgll at 5-leaf

813 stage. Error bars represent the SD. (Student's t-test: * $\mathrm{P}<0.05, * * \mathrm{P}<0.01$ )

814 (B) Real time RT-PCR examination of chloroplast development and photosynthesis

815 related genes in WT and Ospgll at 5-leaf stage. Error bars represent the SD.

$816 \quad$ (Student's t-test: $* * \mathrm{P}<0.01)$

817

818 Figure 10. Alignment of PPR motifs of OsPGL1 with the cis-elements

819 (A) Sequence logo for PPR motifs in OsPGL1, the two positions that contribute to 820 RNA binding specificity was indicated by stars. Sequence logos were constructed 821 by Web-Logo.

822 (B) Alignment of amino acid residues at position 6 and 1' in each neighboring PPR 823 motif of OsPGL1 with the putative cis-elements surrounding the editing sites. 824 Nucleotides matching the PPR-RNA recognition combination were marked in 825 red. 

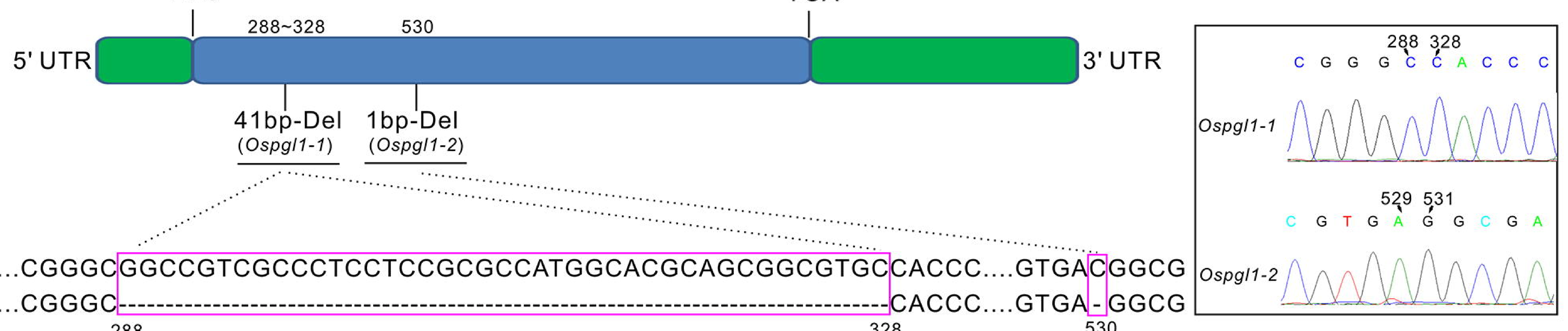

ATG....CGGGCGGCCGTCGCCCTCCTCCGCGCCATGGCACGCAGCGGCGTGCCACCC....GTGÄ̈GGCG ATG....CGGGC-... 328 530
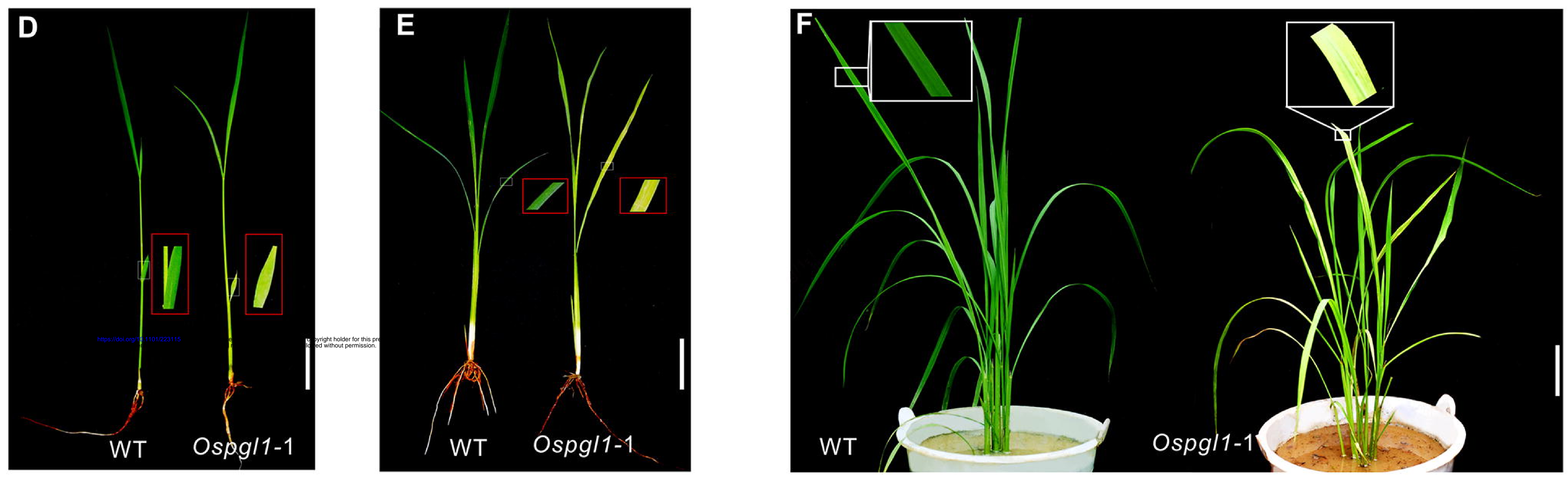

G

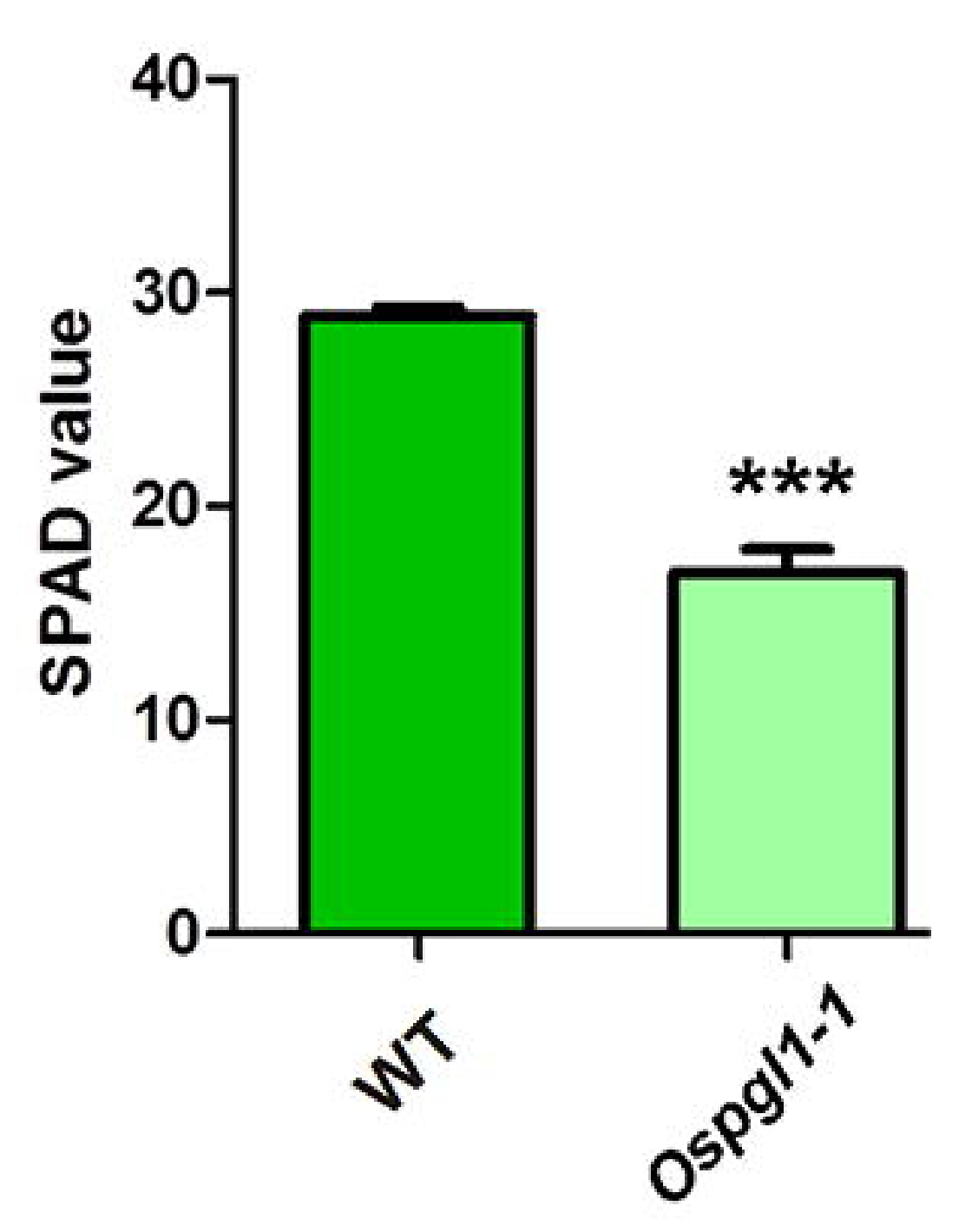

H

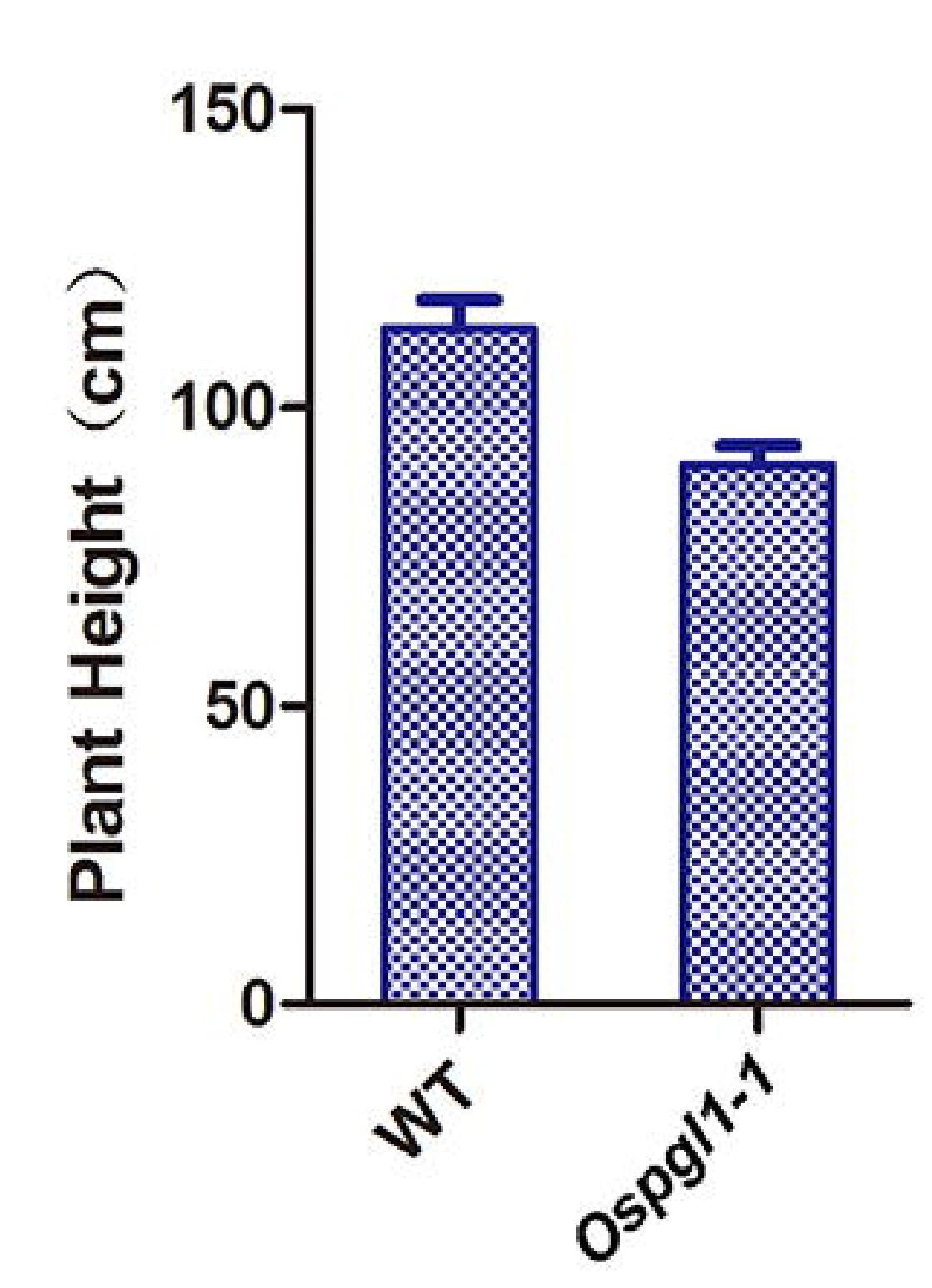

J

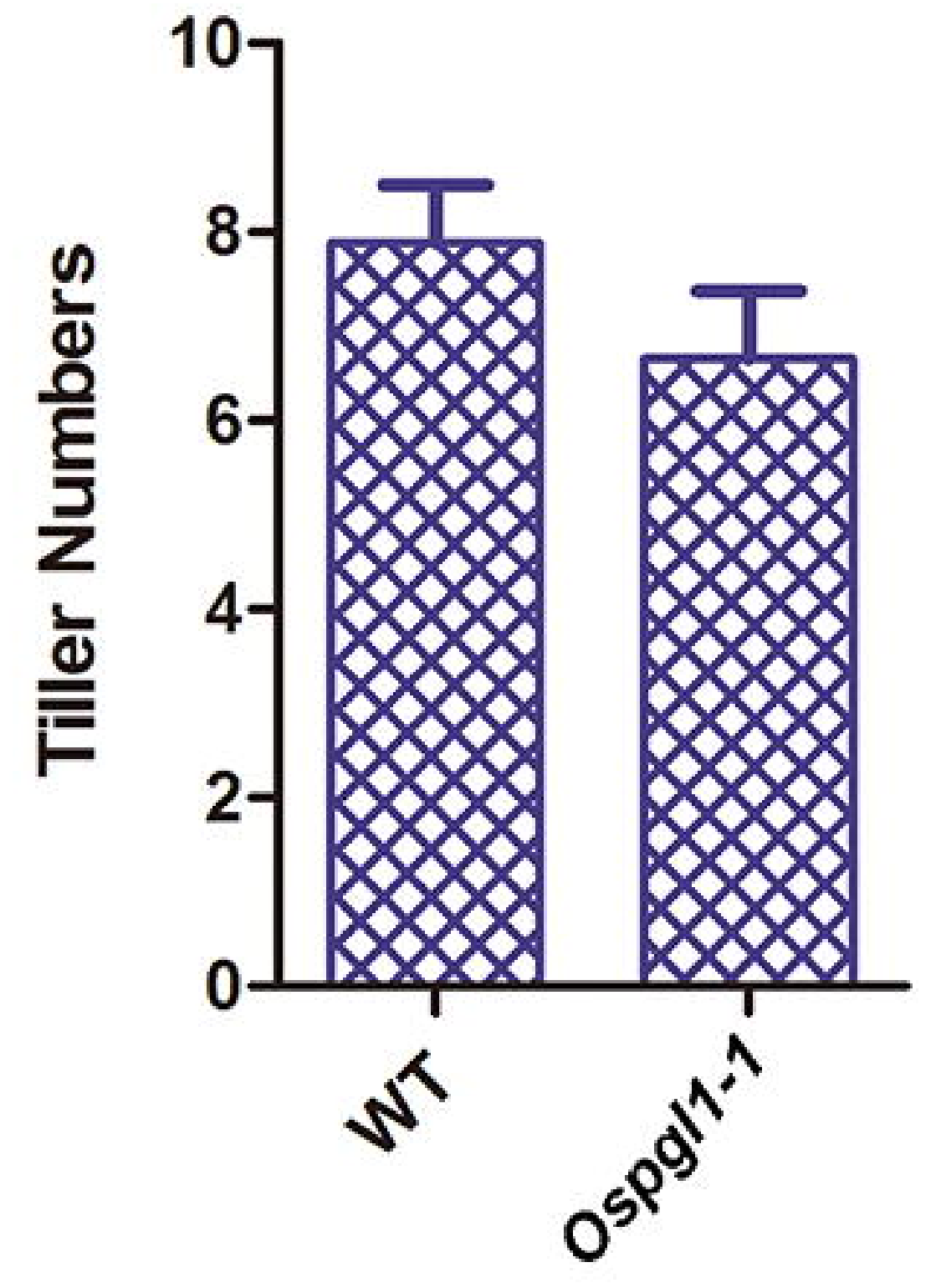









\section{$\begin{array}{lllllll}R & \mathrm{~S} & \mathrm{~L} 3 & \mathrm{~L} 4 & \mathrm{~L} 5 & \mathrm{P}\end{array}$}

OSPGL1

Ubi
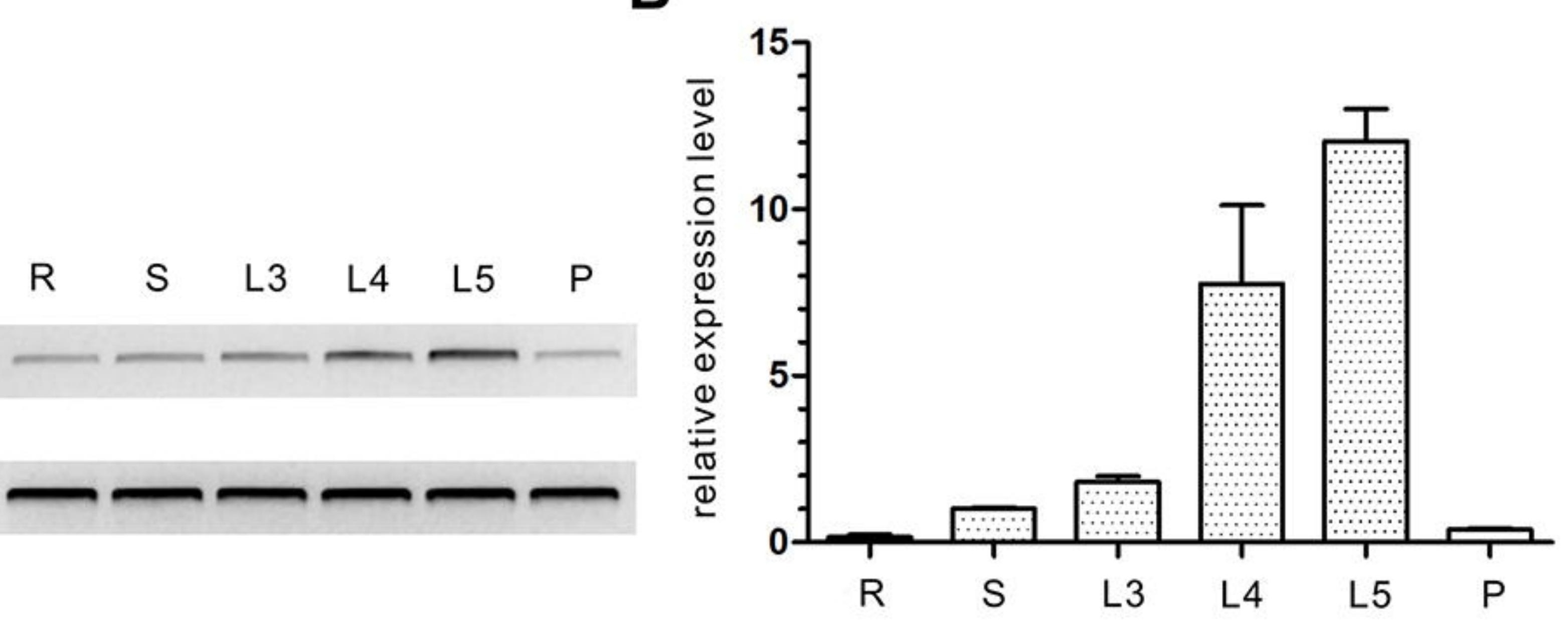

Bright Field

GFP

Chlorophyll

Merged

bioRxiv preprint doi: https://doi.org/10.1101/223115; this version posted November 21, 2017. The copyrig sGFP

OsPGL $1^{\mathrm{N} 1-188}$-sGFP

D
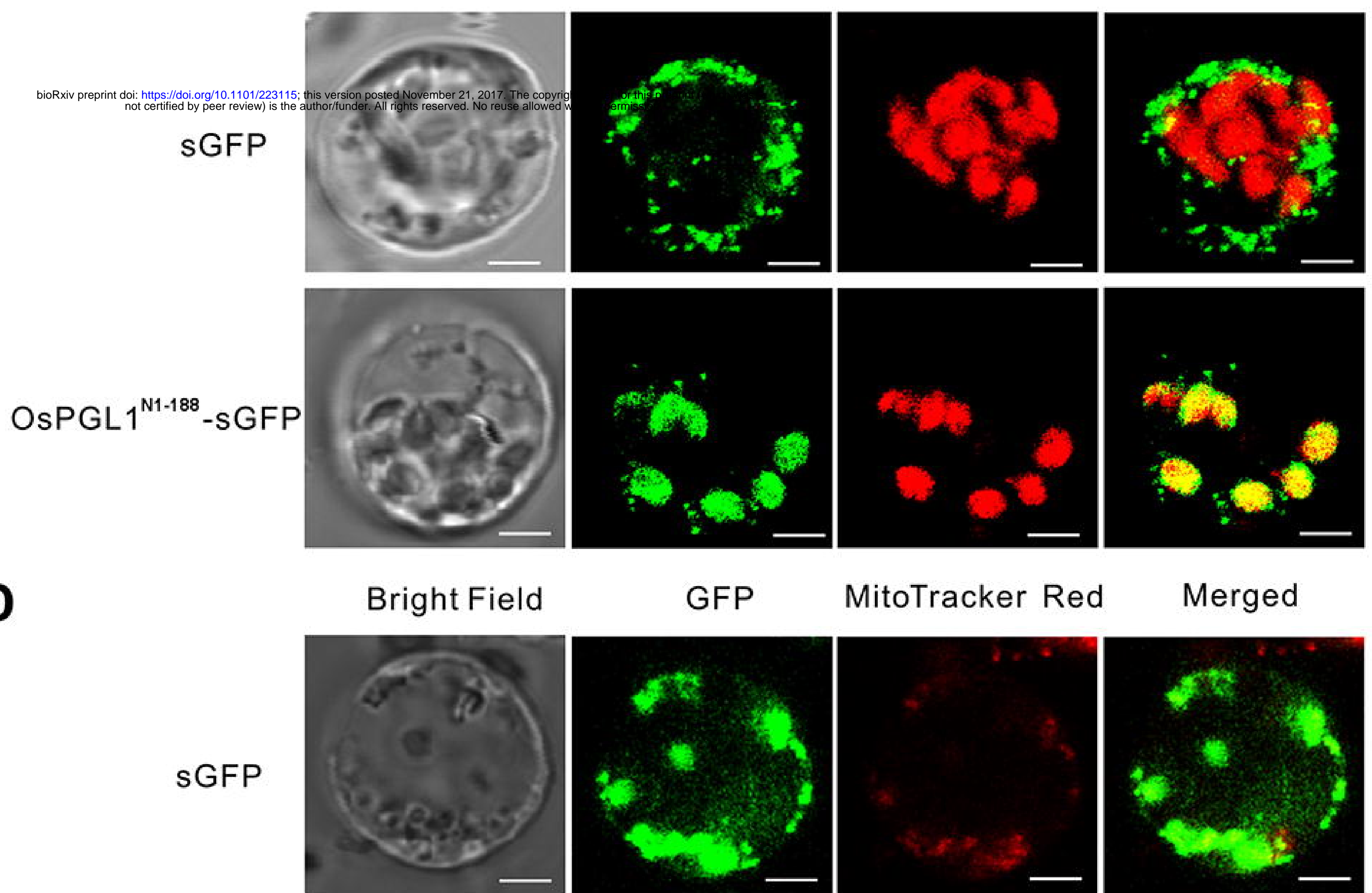

GFP

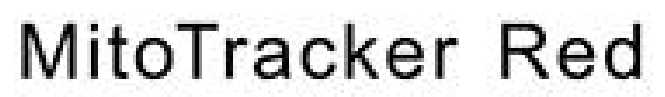

Merged
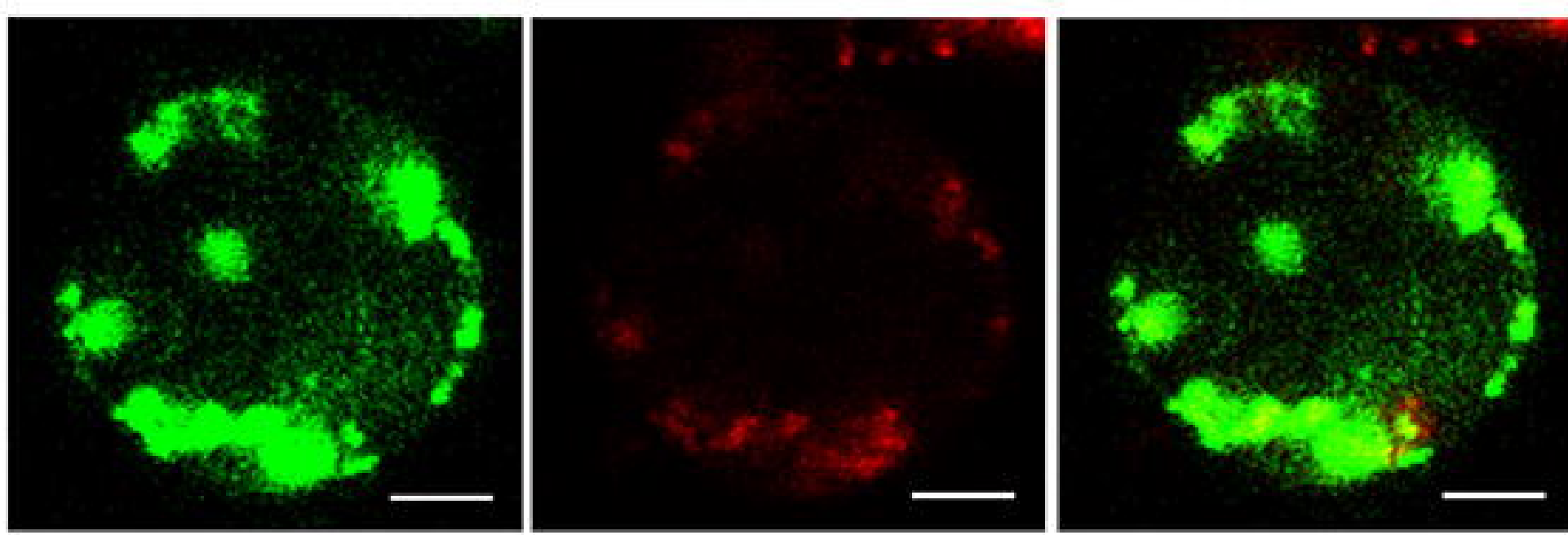

OsPGL $1^{\mathrm{N} 1-188}-\mathrm{sGFP}$
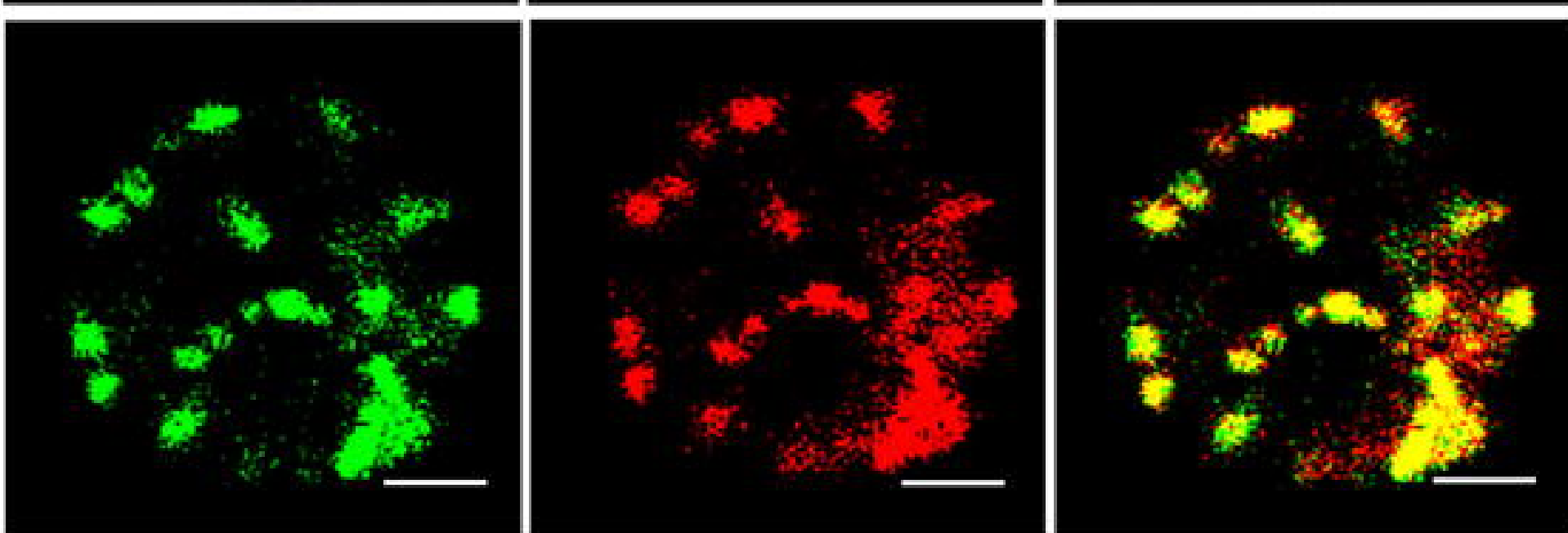


\section{A}
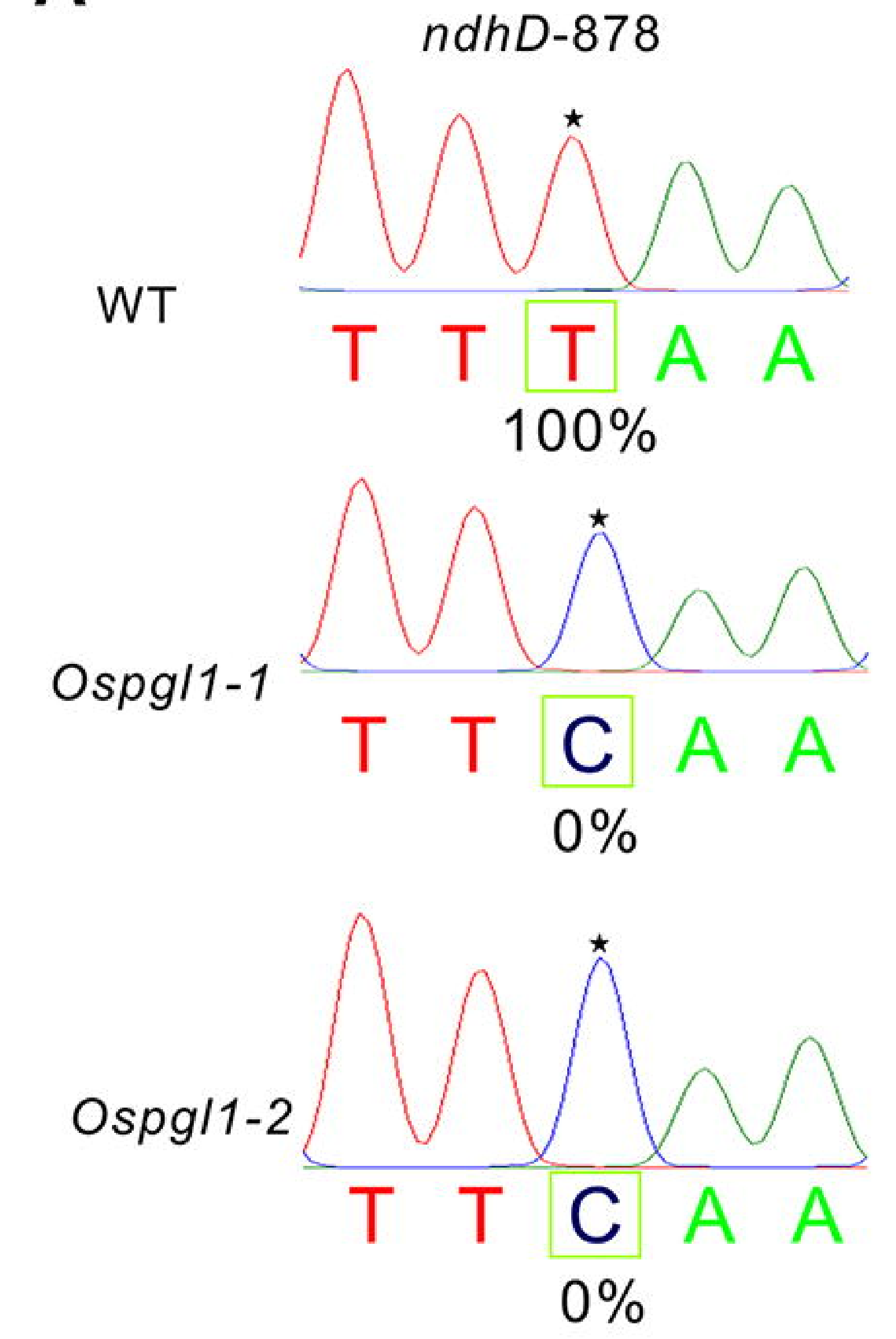

ccmFc-543
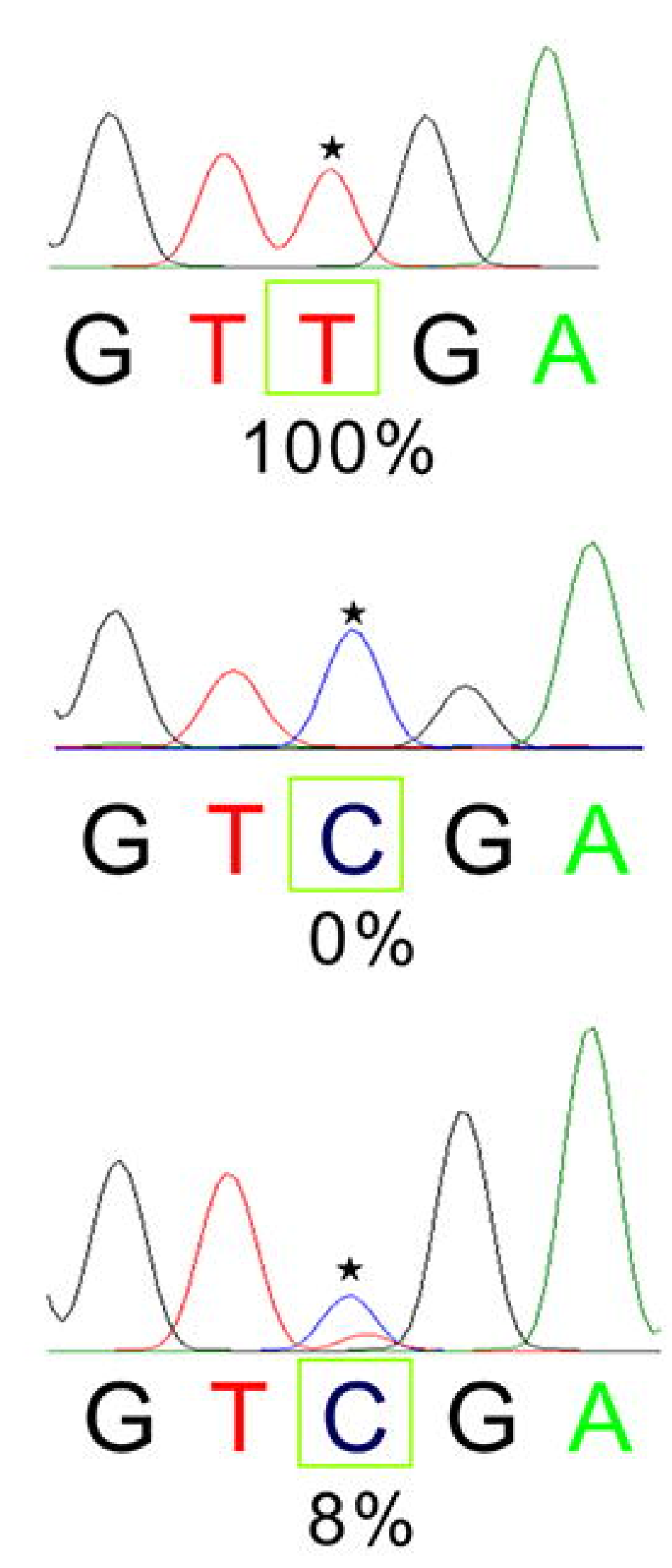

NdhD-293
Oryza sativa

Zea mays

Arabidopsis thaliana

Nicotiana tabacum

Brassica napus

Oryza sativa

Zea mays

Arabidopsis thaliana

Nicotiana tabacum

Brassica napus
GAMQ I I Y A A L T S L G Q R NF K G A VQ I I Y A A L T S L G Q R NFK G T I Q I I Y A A L T S L G Q R N L K G T I Q I I Y A A L T S L G Q R N L K G T I Q I I Y A A L T S P G Q R N L K

$\mathrm{ccmFc}-181$

H P H I - E R R V E F G P VA F P H P H I - ER RVE G F G P VA F P H P H L D L E R R V E G F G P LA F P H P H L - E R RVE G F G PA F P H P H LD LE R R VE G F G P LA F P 
Probe1: AGUGAUGCAAAUAAUCUAUGCAGCUUCAACUUCUC

$c c m F c-543$
Probe2: GGGCACCCCCAUAUAGAAAGAAGGGUĆGAAGGUUU nad3-155

ProbeC: GUAUCUAUUUAGUGAUCAGUCĆGCUAGUUUCUUUG

B

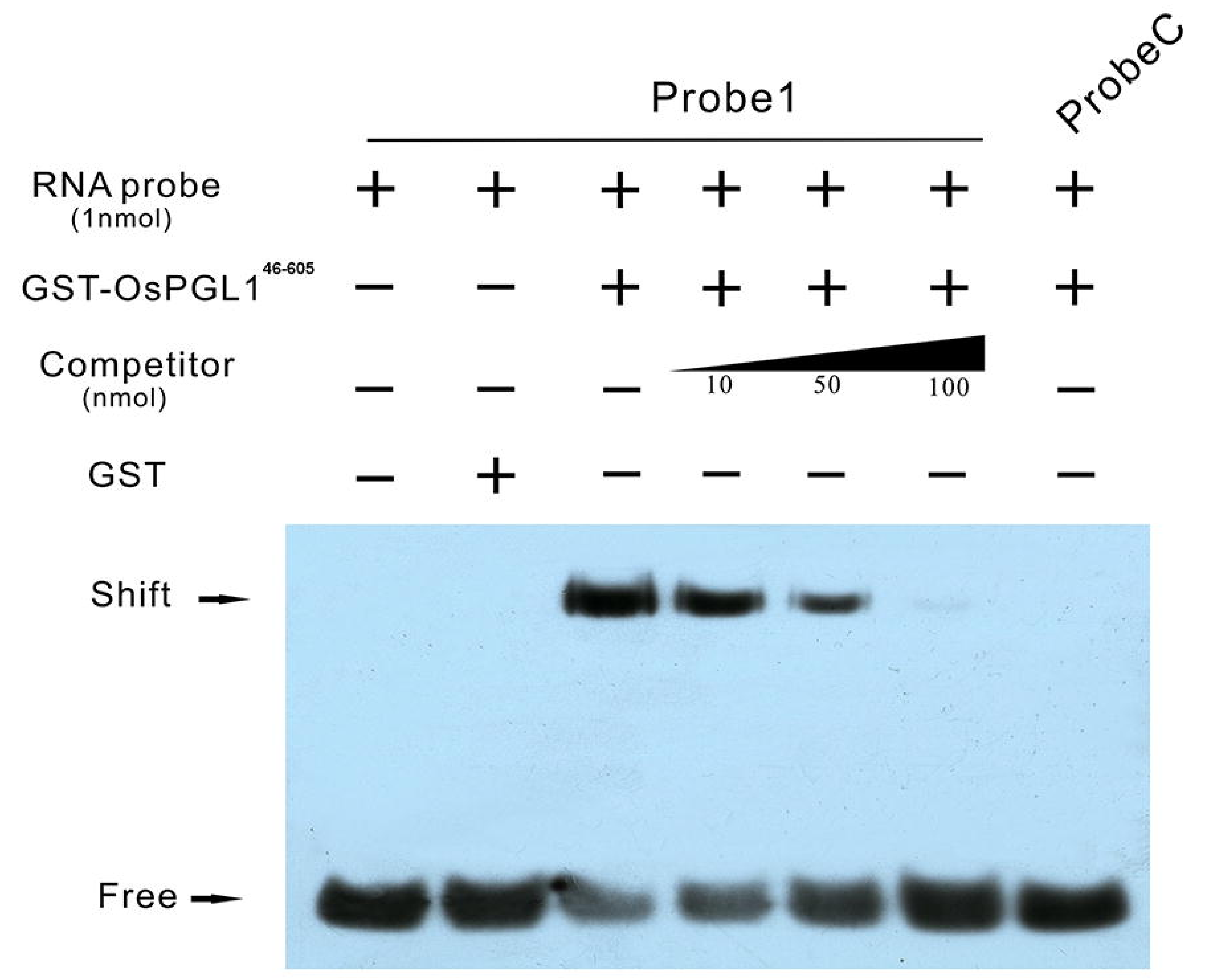

C

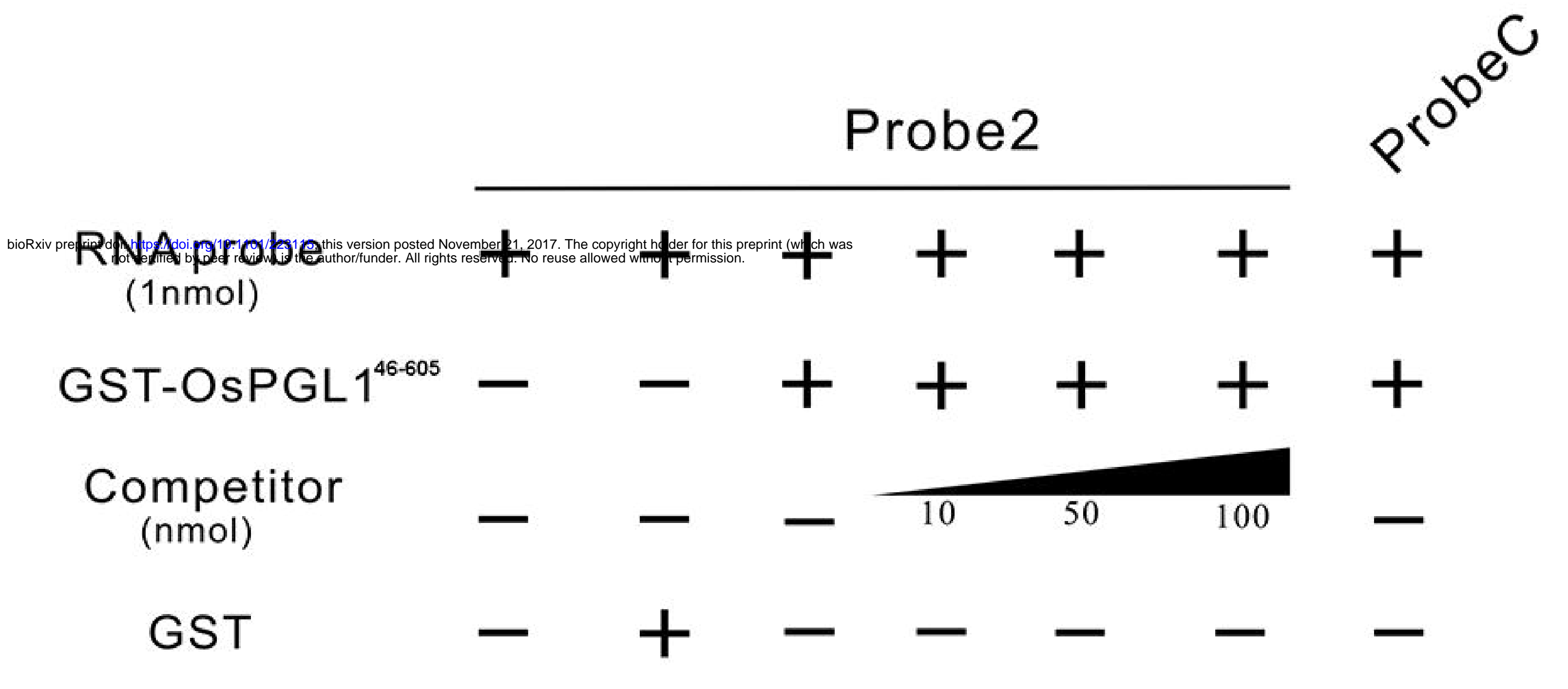

Shift $\rightarrow$

Free -

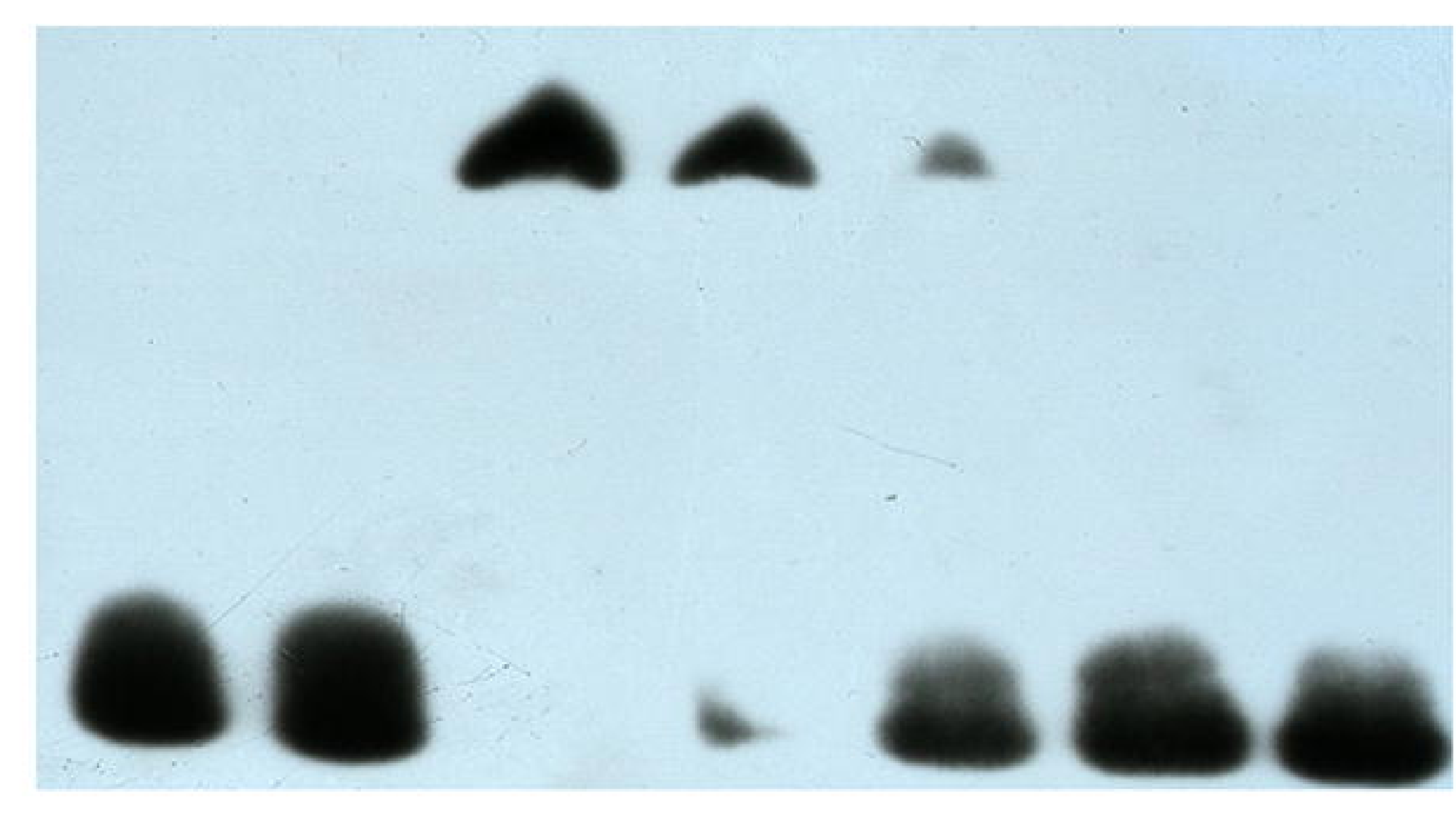




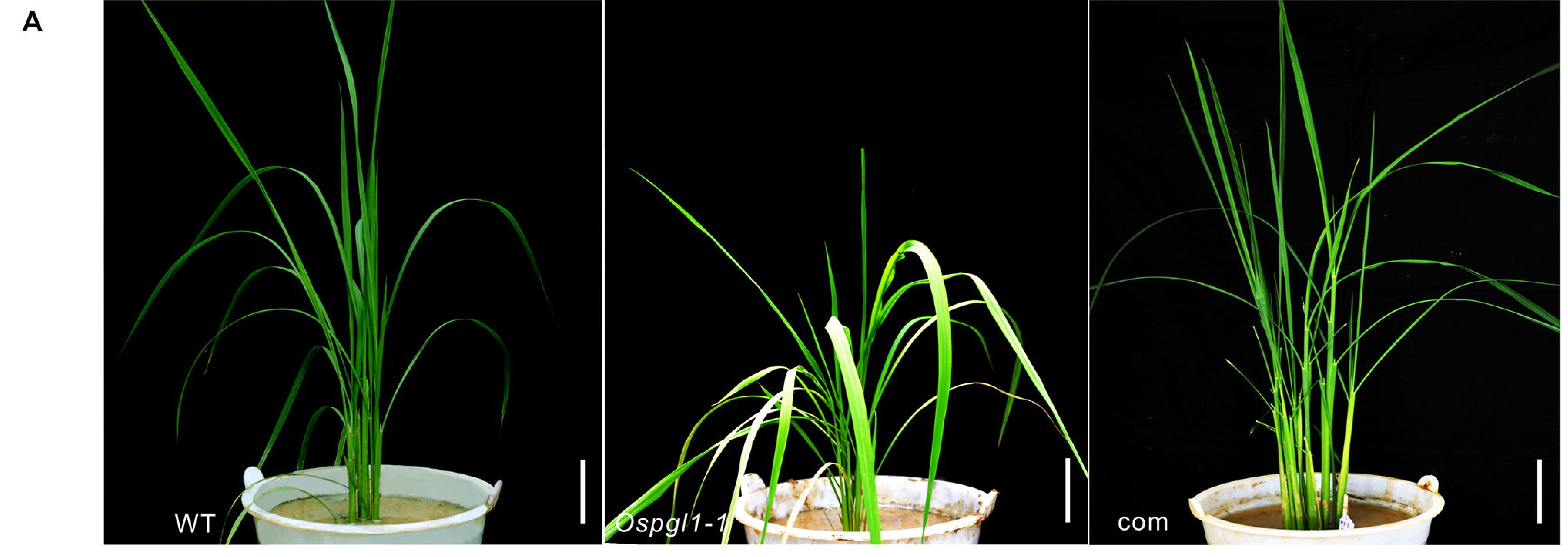

B

$n d h D-878$
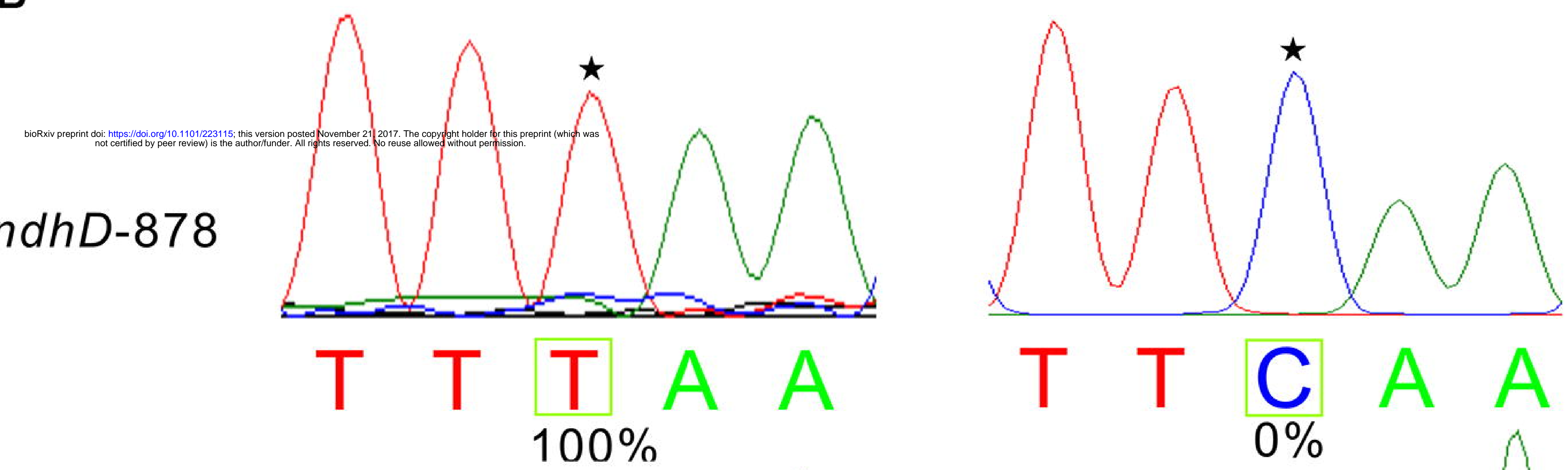

ccmFc-543

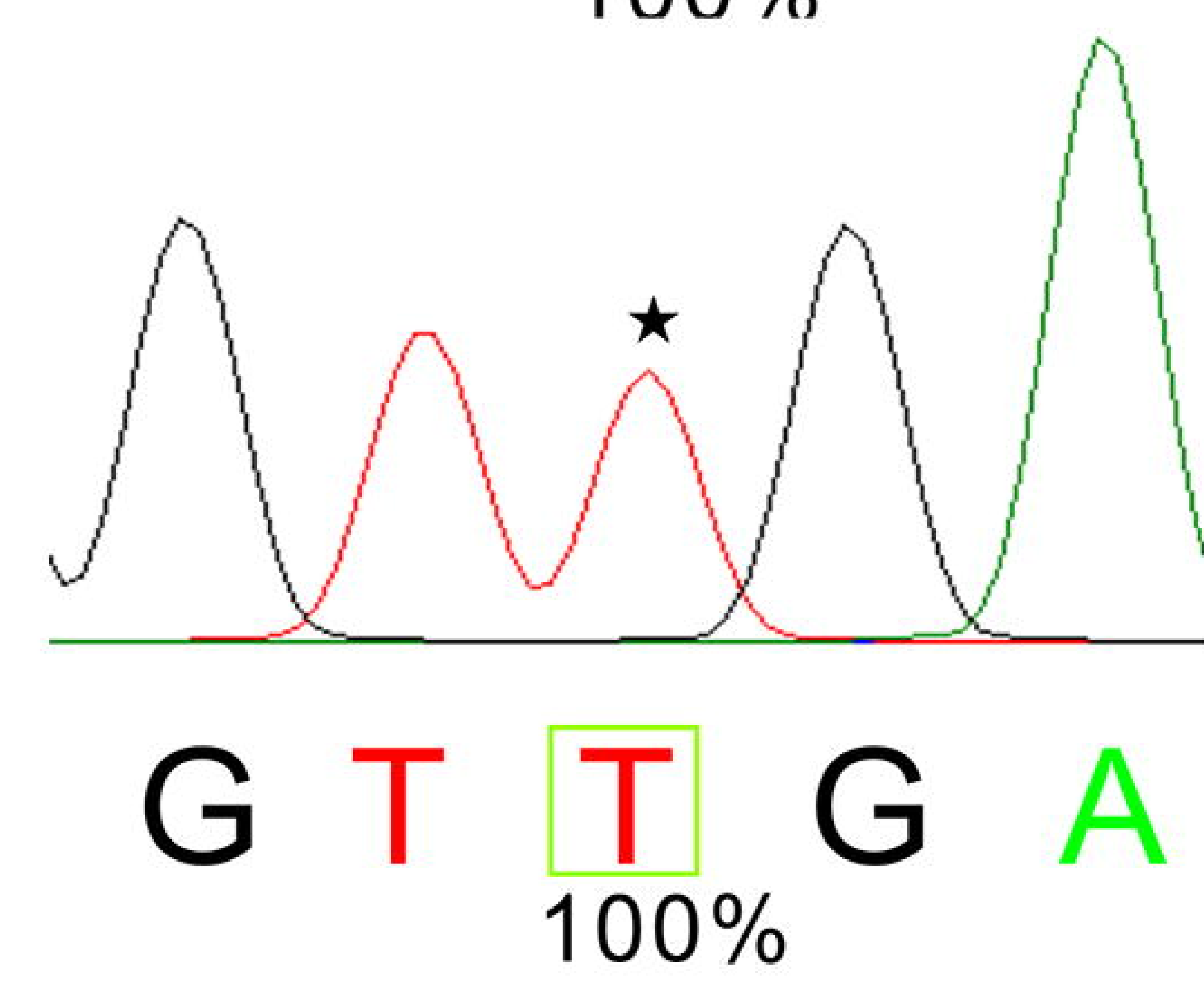

T T

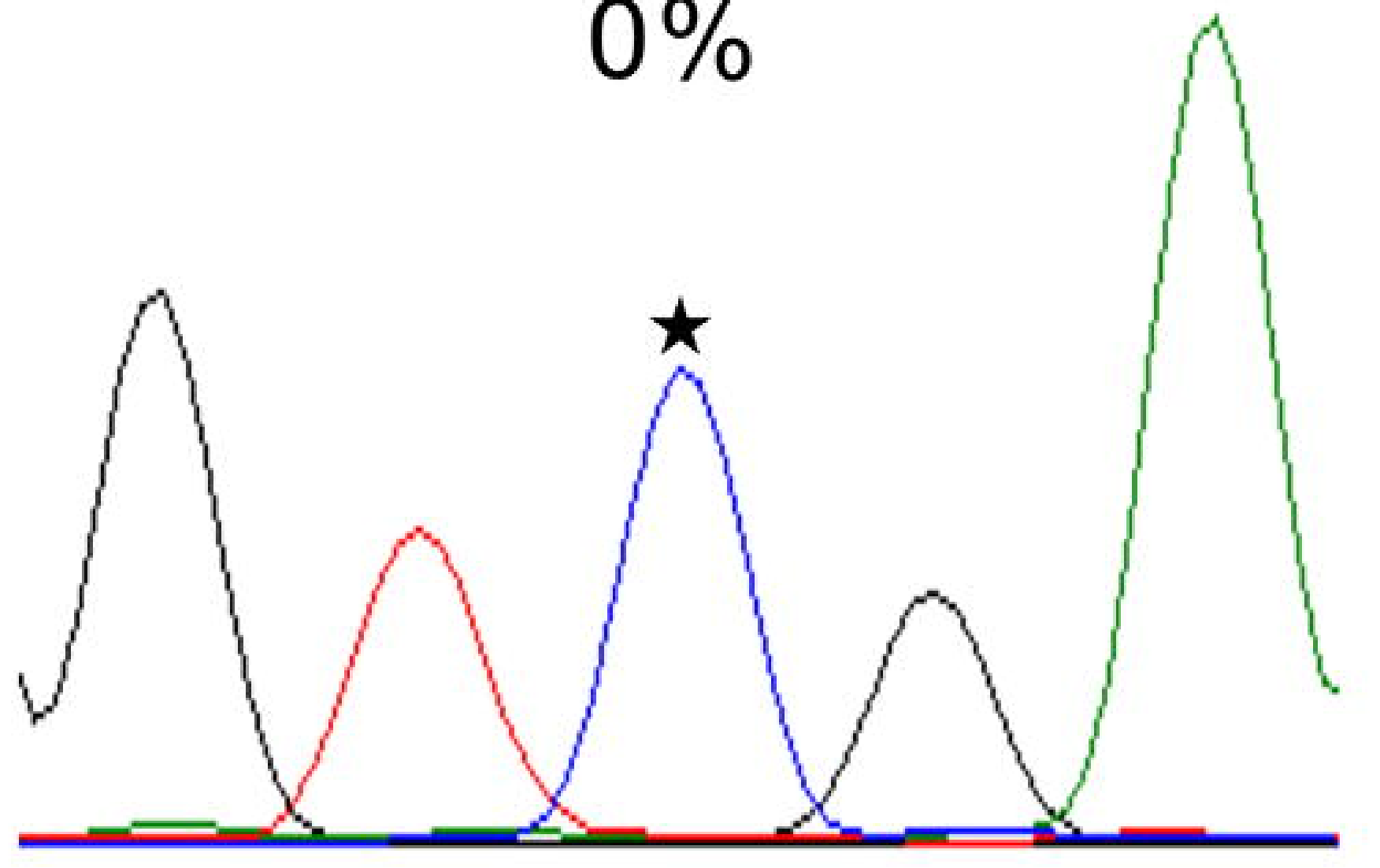

$G \mathrm{C} \underset{0 \%}{\mathrm{C}} \mathrm{G} A$

Ospgl1-1
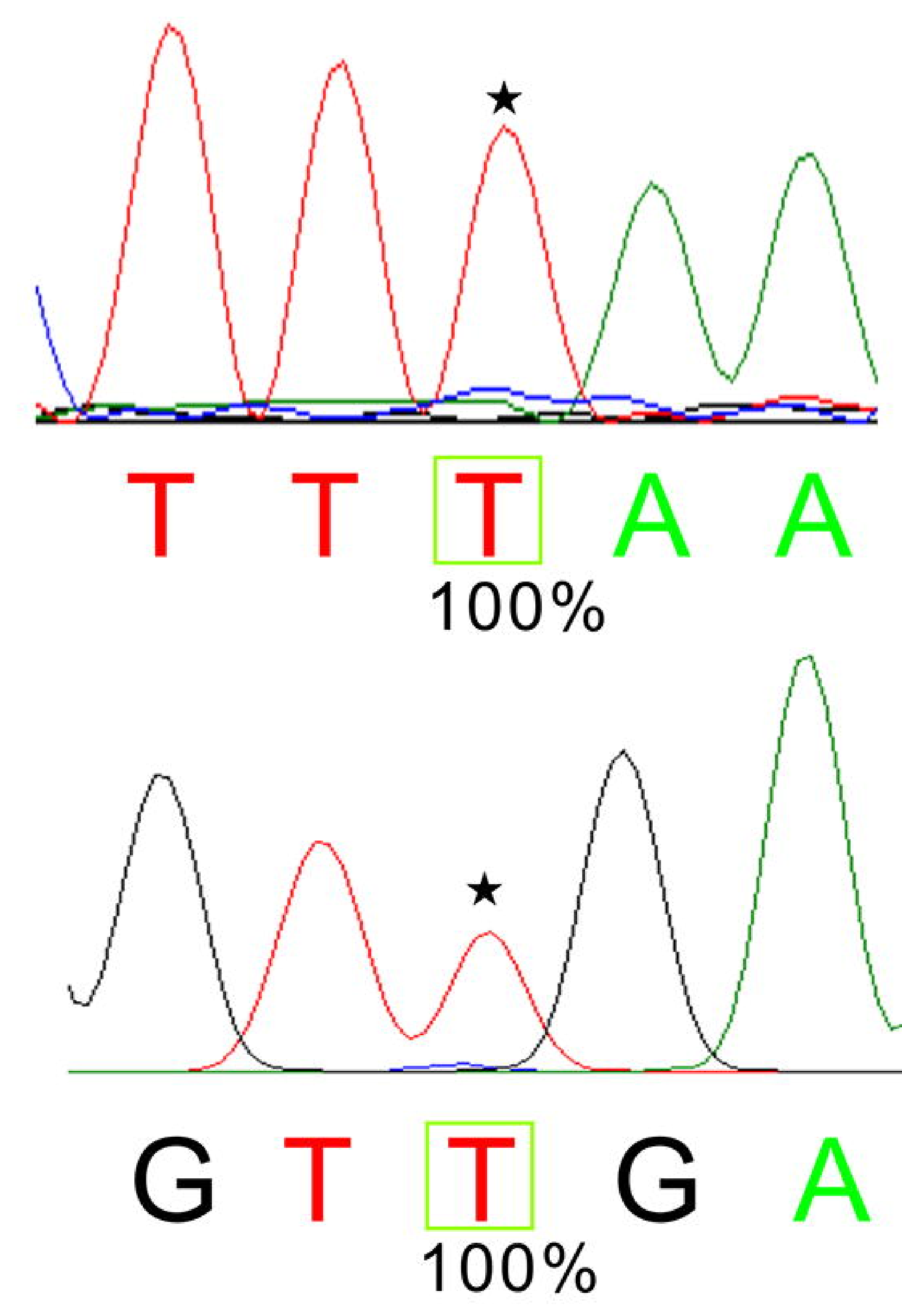

com 
A

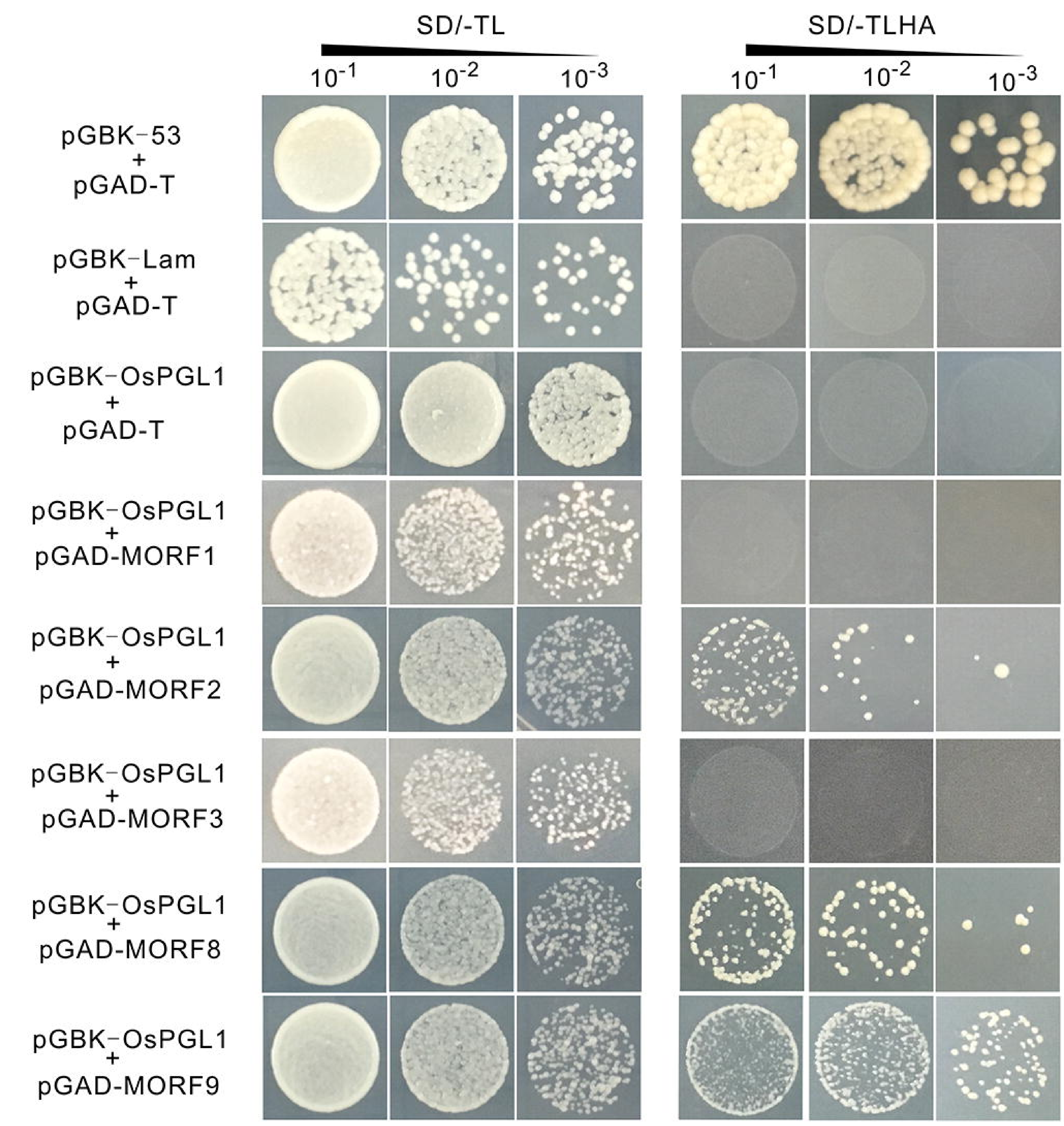

B

$\begin{array}{ccccc}\text { GST } & + & + & - & - \\ \text { GST-OSPGL1 } & - & - & + & + \\ \text { Trx-His } & + & - & + & - \\ \text { Trs-MORF2-His } & - & \mathbf{+} & - & \mathbf{+}\end{array}$

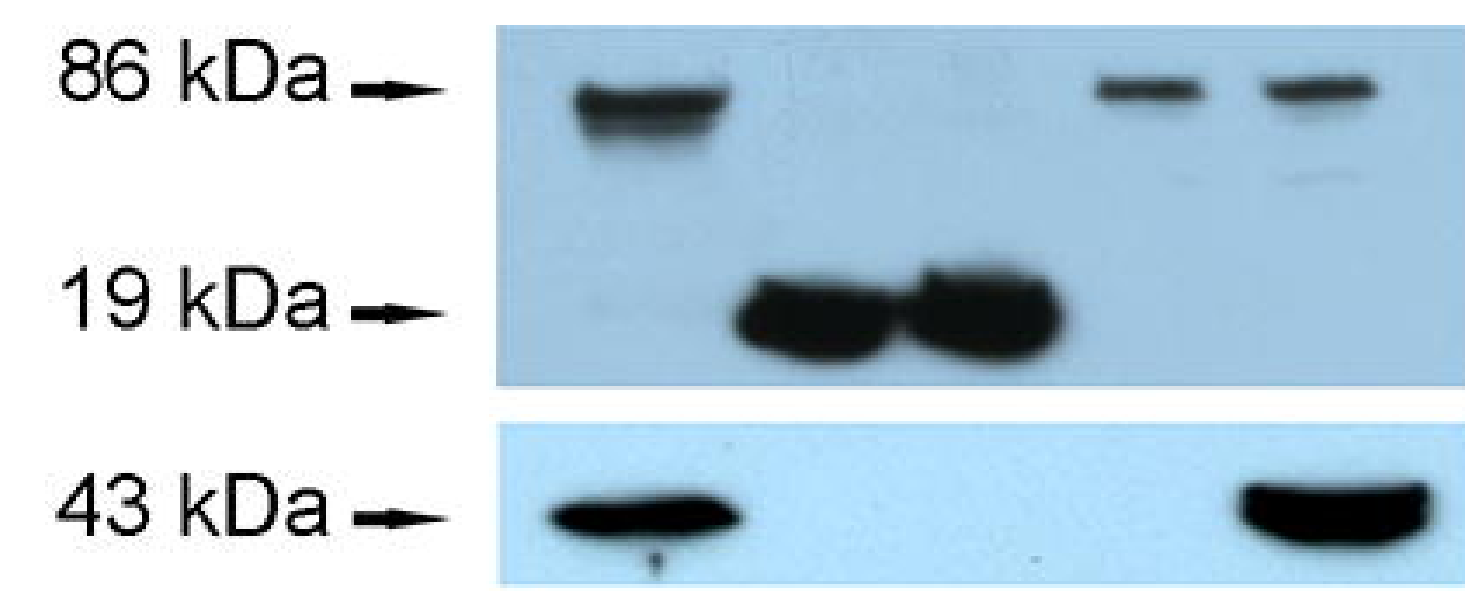
anti-GST anti-His

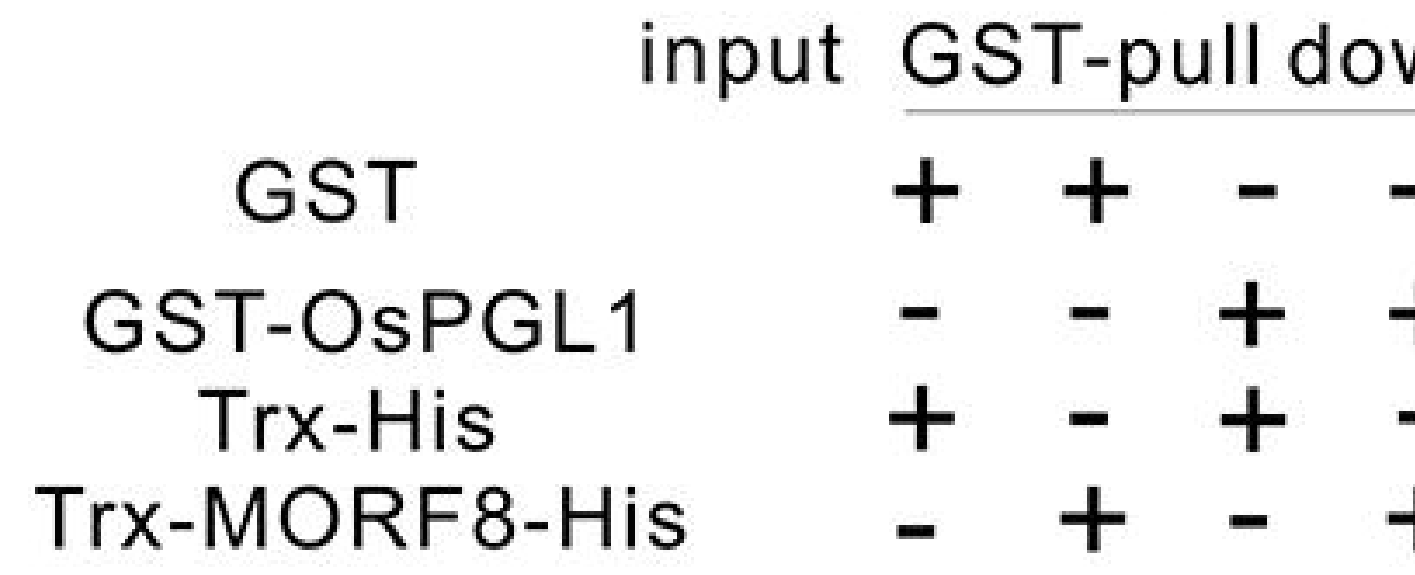

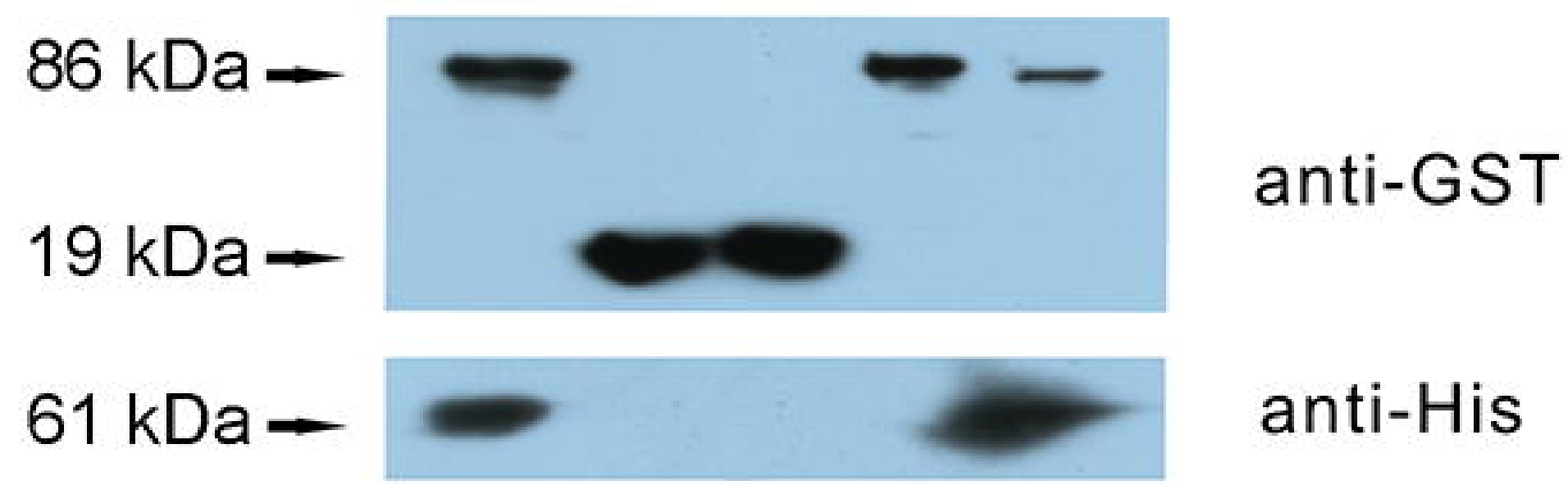

input GST-pull down

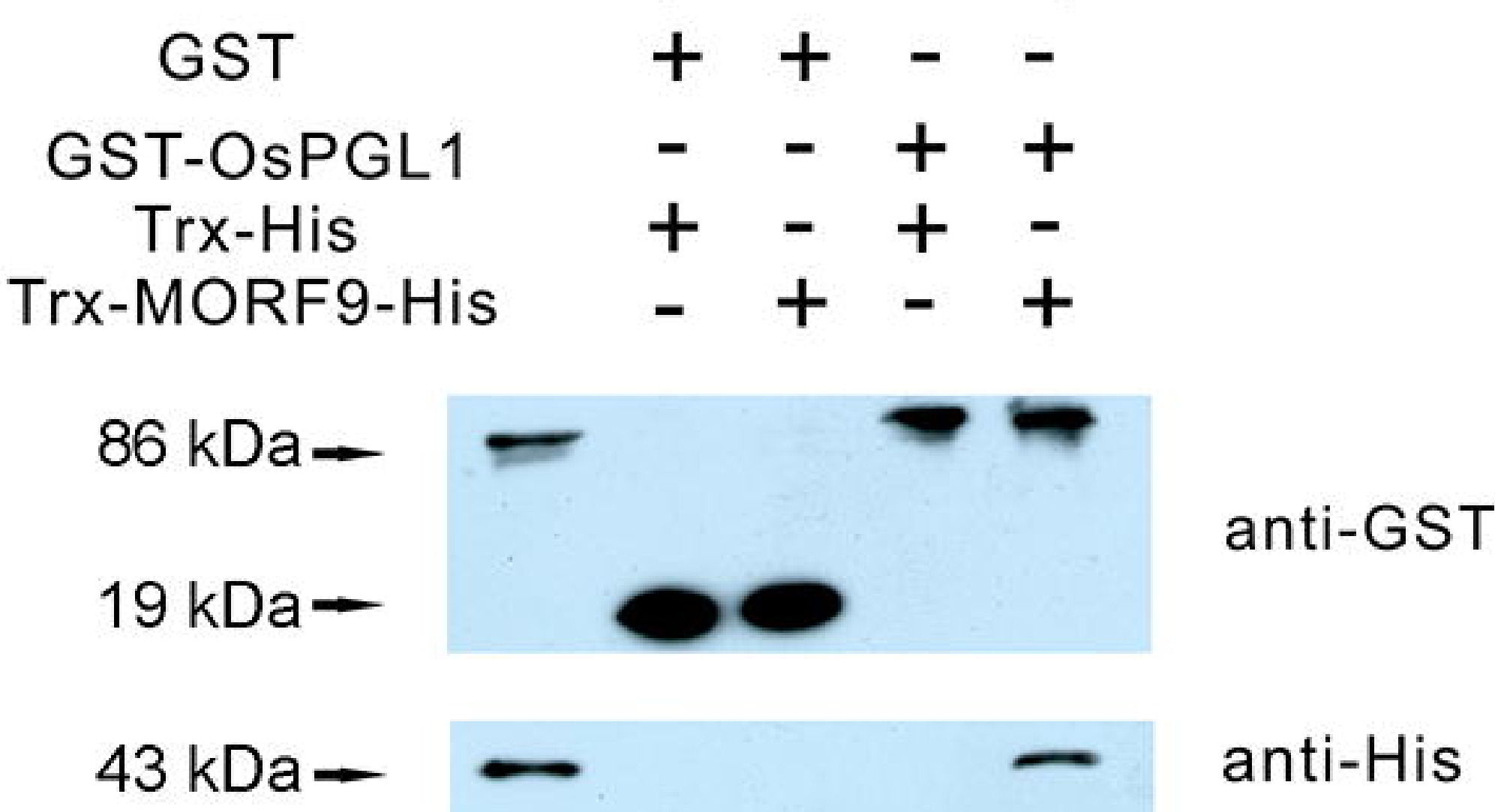

C

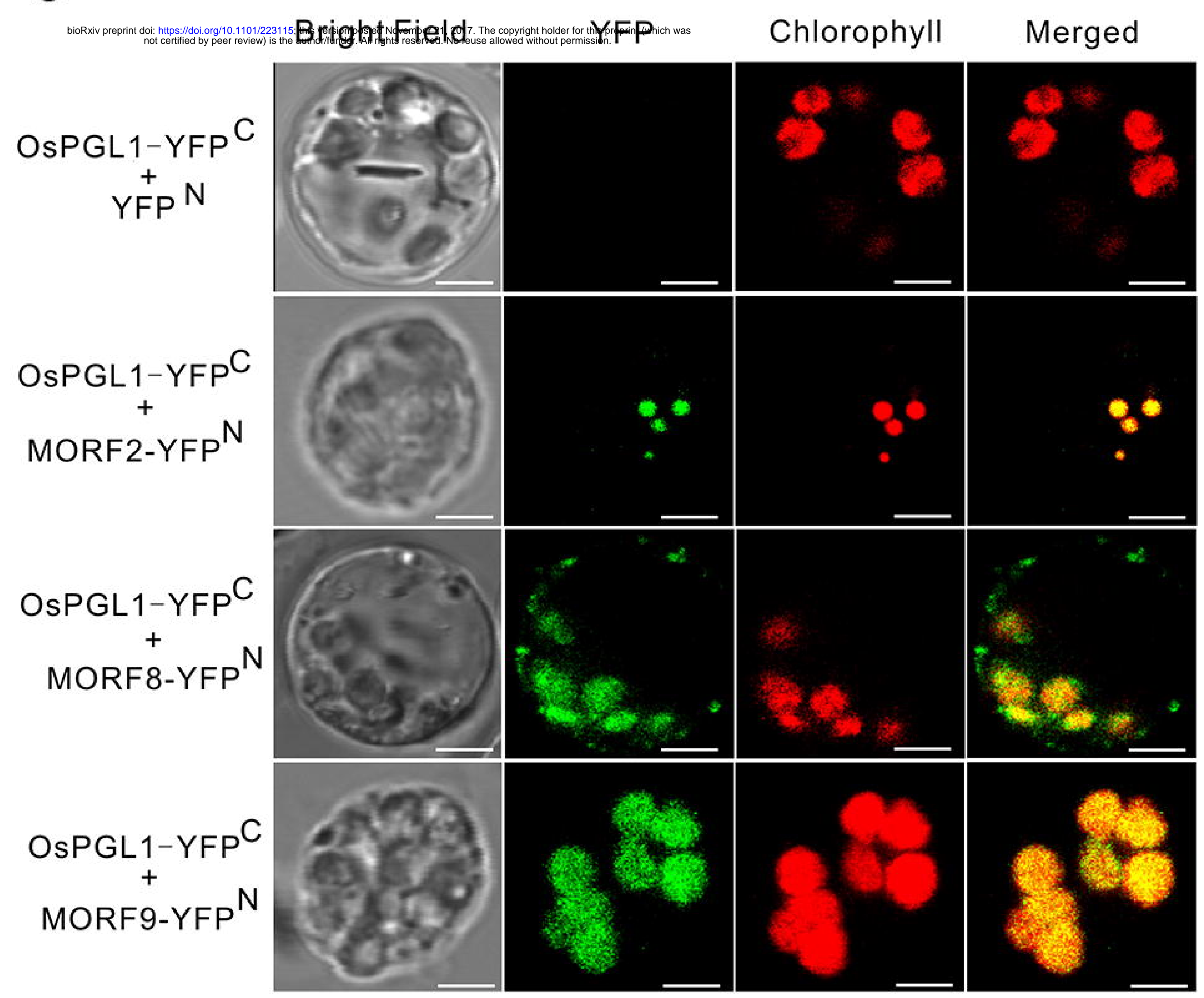

D

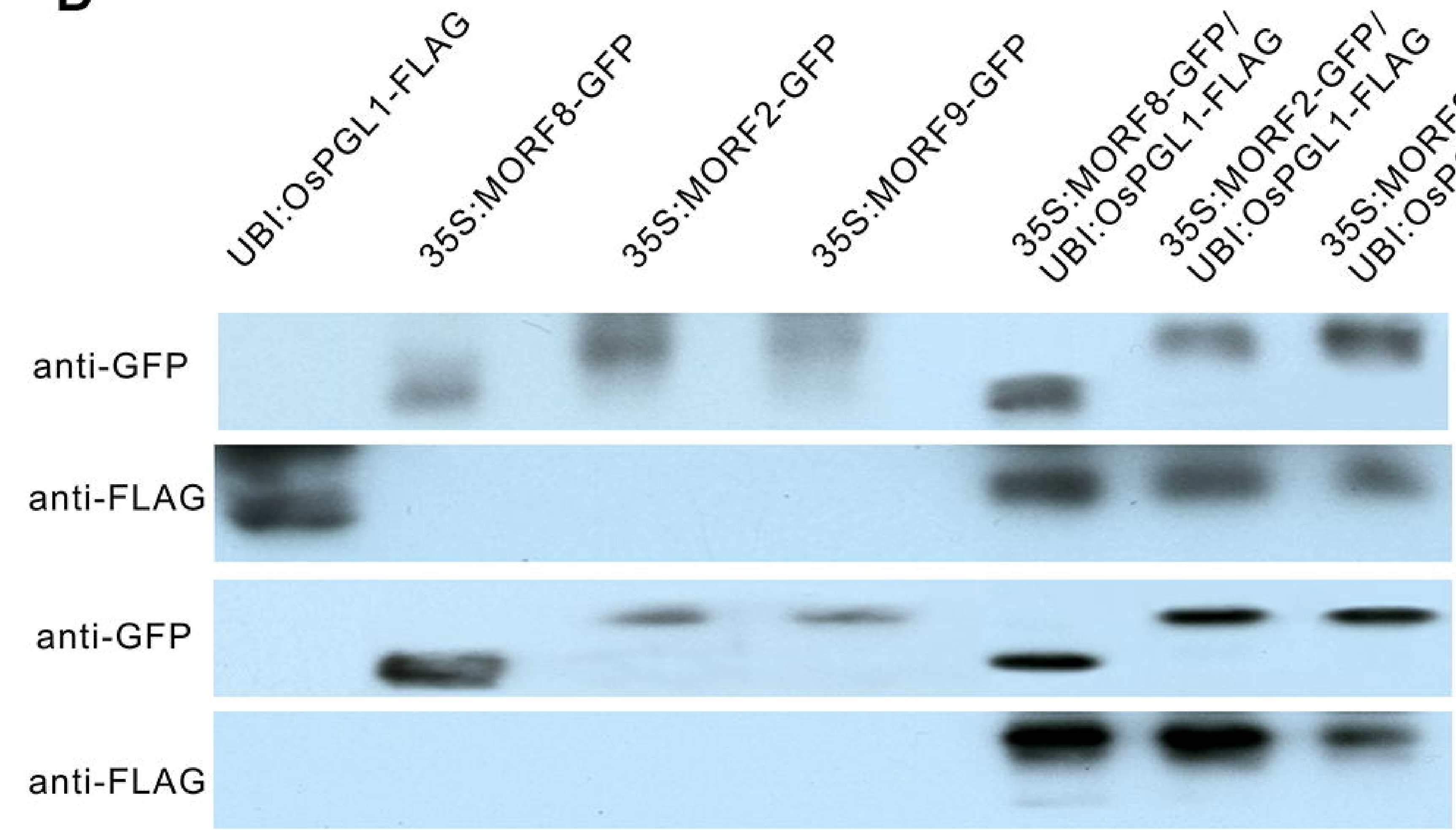

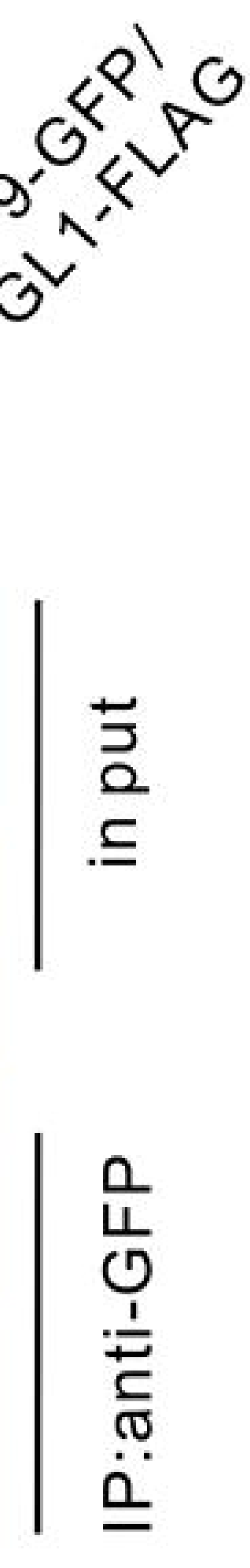




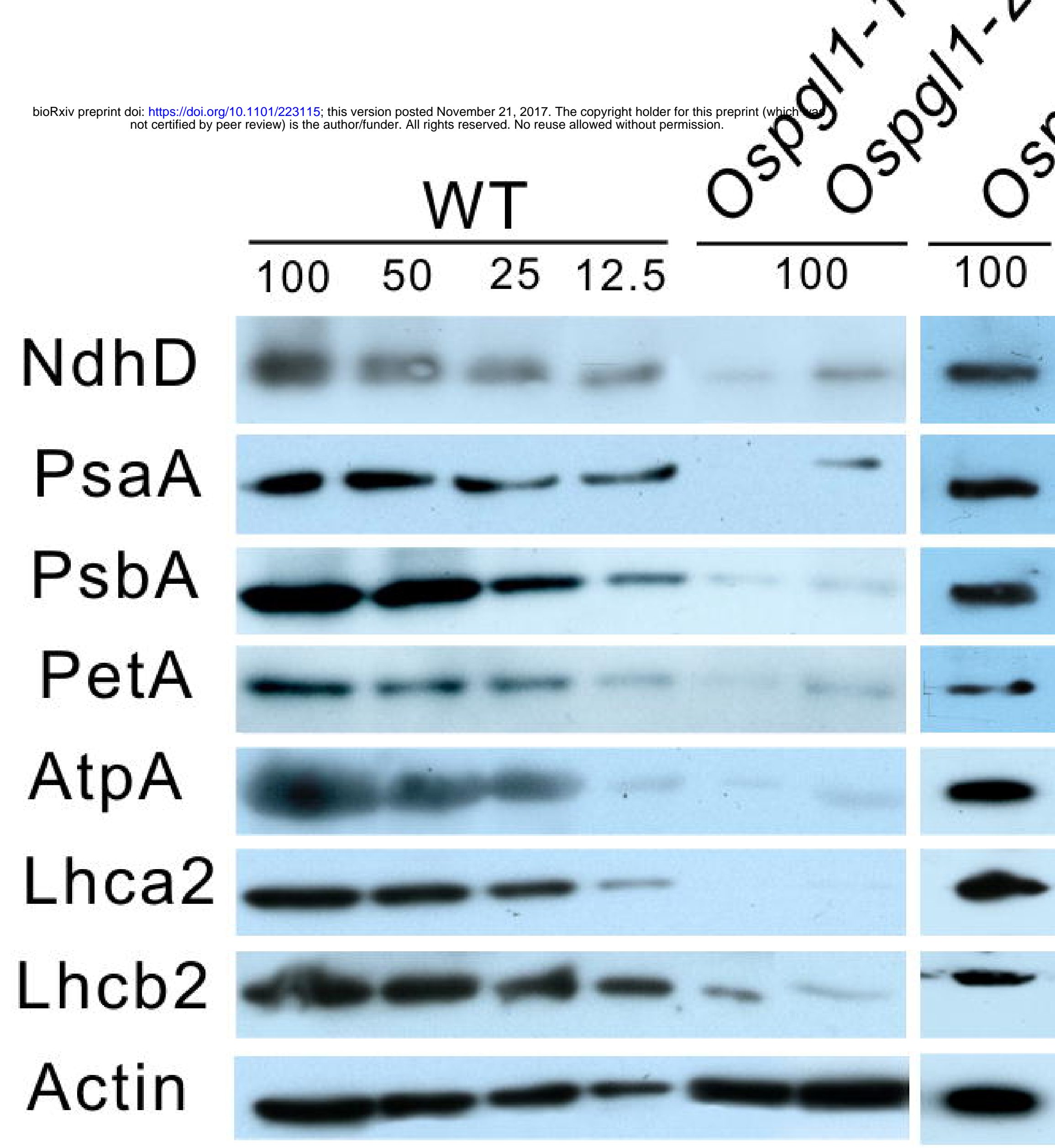

CBB

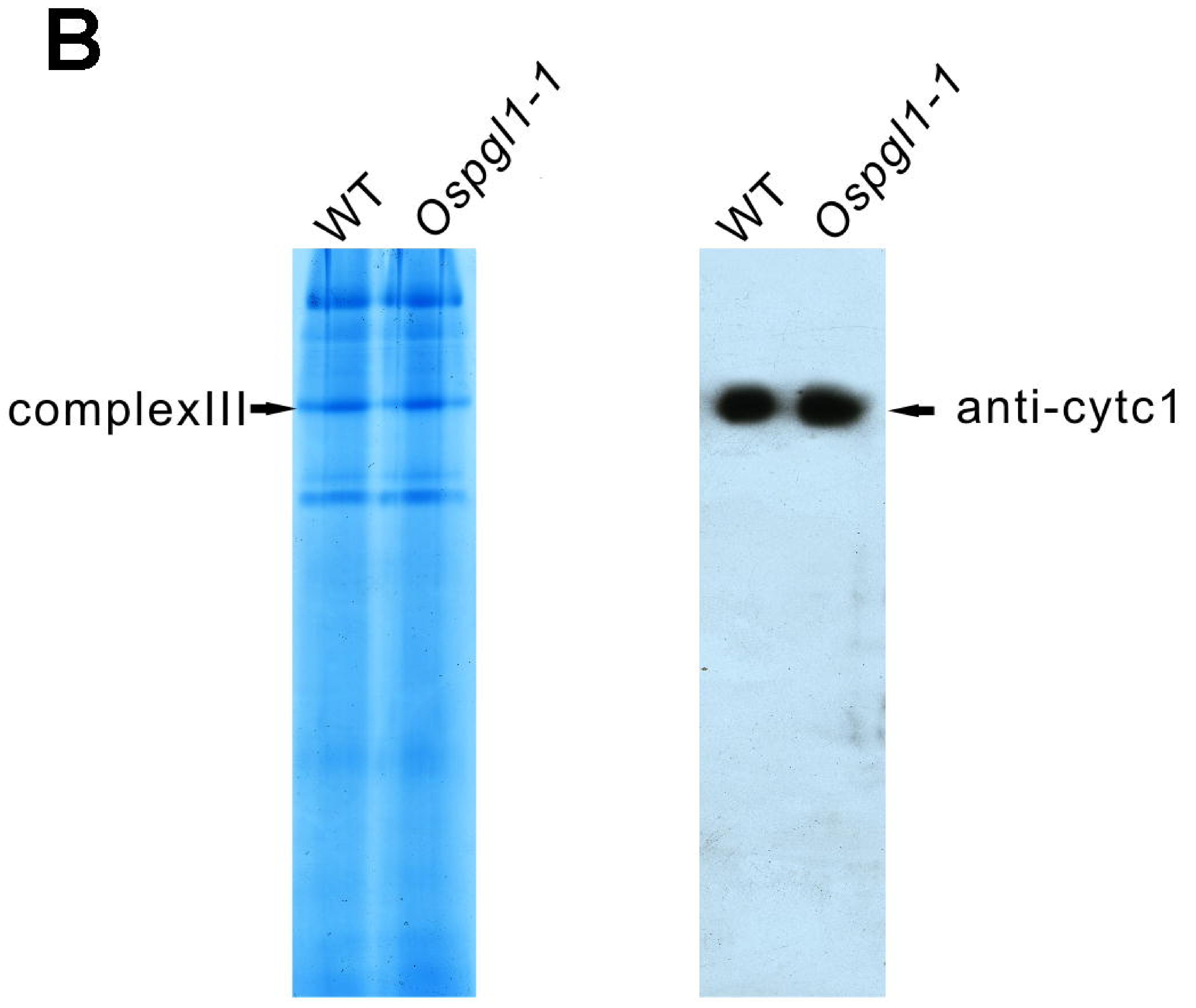


A
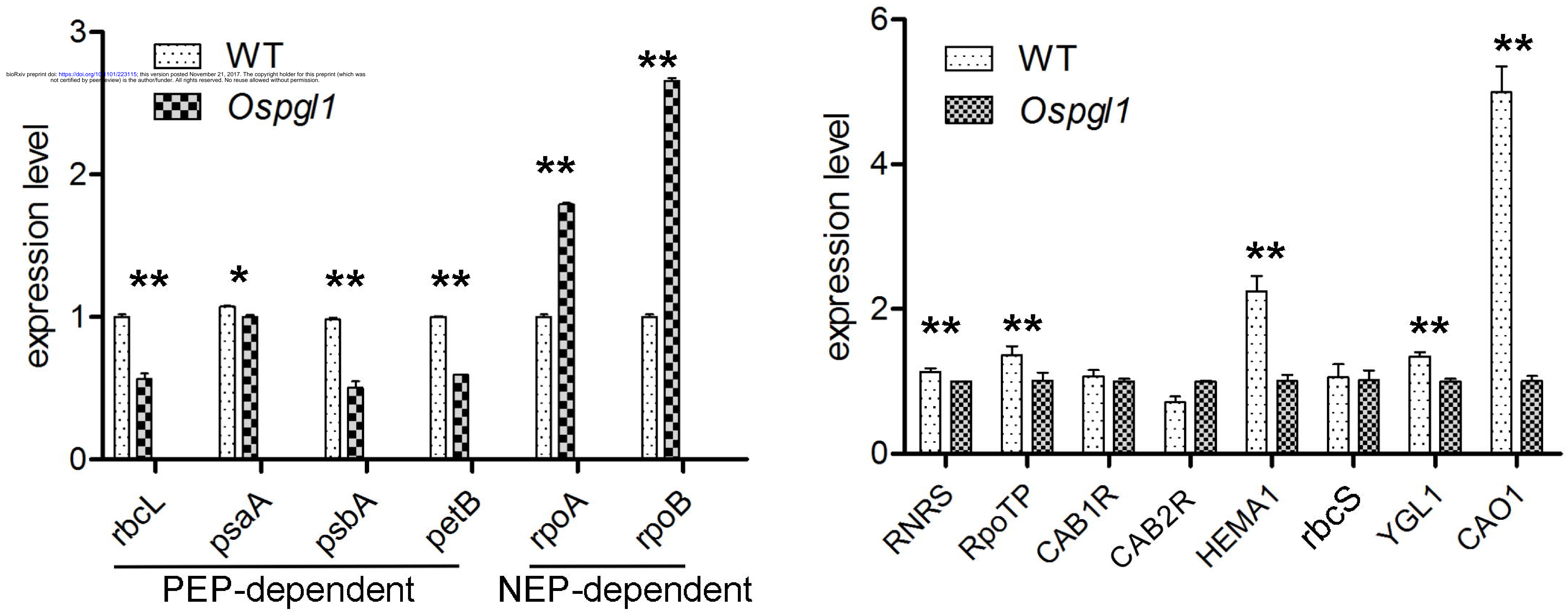
